\title{
Distinct Amino Acids \\ of the Phytophthora infestans Effector AVR3a Condition Activation of R3a Hypersensitivity and Suppression of Cell Death
}

\author{
Jorunn I. B. Bos,,$^{1,2}$ Angela Chaparro-Garcia, ${ }^{1,2}$ Lina M. Quesada-Ocampo, ${ }^{1}$ \\ Brian B. McSpadden Gardener, ${ }^{1}$ and Sophien Kamoun ${ }^{1,2}$ \\ ${ }^{1}$ Department of Plant Pathology, The Ohio State University, Ohio Agricultural Research and Development Center, Wooster, \\ OH 44691, U.S.A.; ${ }^{2}$ The Sainsbury Laboratory, Colney Lane, Norwich, NR4 7UK, U. K.
}

Submitted 10 October 2008. Accepted 21 November 2008.

\begin{abstract}
The AVR3a protein of Phytophthora infestans is a polymorphic member of the RXLR class of cytoplasmic effectors with dual functions. AVR3a ${ }^{\mathrm{KI}}$ but not $\mathrm{AVR}^{\mathrm{E}} \mathrm{a}^{\mathrm{EM}}$ activates innate immunity triggered by the potato resistance protein R3a and is a strong suppressor of the cell-death response induced by INF1 elicitin, a secreted $P$. infestans protein that has features of pathogen-associated molecular patterns. To gain insights into the molecular basis of AVR3a activities, we performed structure-function analyses of both AVR3a forms. We utilized saturated high-throughput mutant screens to identify amino acids important for R3a activation. Of 6,500 AVR3a $^{\text {EM }}$ clones tested, we identified 136 AVR3a $^{\text {EM }}$ mutant clones that gained the ability to induce R3a hypersensitivity. Fifteen amino-acid sites were affected in this set of mutant clones. Most of these mutants did not suppress cell death at a level similar to that of AVR3a ${ }^{\mathrm{KI}}$. A similar loss-of-function screen of 4,500 AVR3a ${ }^{\mathrm{KI}}$ clones identified only 13 mutants with altered activity. These results point to models in which AVR3a functions by interacting with one or more host proteins and are not consistent with the recognition of AVR3a through an enzymatic activity. The identification of mutants that gain R3a activation but not cell-death suppression activity suggests that distinct amino acids condition the two AVR3a effector activities.
\end{abstract}

Similar to bacterial plant pathogens, eukaryotic plant pathogens secrete an arsenal of effector proteins that modulate host innate immunity and enable parasitic infection (Kamoun 2007). Deciphering the biochemical activities of effectors to understand how pathogens successfully colonize and reproduce on their host plants has become a driving paradigm in the field of fungal and oomycete pathology. Although effectors primarily function as virulence factors, specific effector molecules can also be recognized by plant disease resistance (R) proteins in particular host genotypes, resulting in activation of effector-triggered immunity. In most cases, this involves the hypersensitive response (HR), a form of programmed cell death, followed by restriction of the invading pathogen (Jones

Corresponding author: Sophien Kamoun; Telephone: +44(0)1603 450410; Fax: +44(0)1603 450011: E-mail: sophien.kamoun@tsl.ac.uk

* The $\boldsymbol{e}$-Xtra logo stands for "electronic extra" and indicates that two supplemental figures and six supplemental tables are published online. and Dangl 2006). Consequently, many pathogen effectors evolved to suppress effector-triggered immunity as well as other forms of plant defenses, such as pathogen-associated molecular pattern (PAMP)-triggered immunity, resulting in a coevolutionary arms race between pathogens and their host plants (Chisholm et al. 2006; Jones and Dangl 2006).

The mechanisms underlying effector recognition by the host involve either direct or indirect interactions of the effectors with their corresponding R proteins (Dangl and Jones 2001; Jones and Dangl 2006; Martin et al. 2003; van der Hoorn and Kamoun 2008). For example, the AvrL567 effectors from the flax rust fungus Melampsora lini are recognized by their cognate flax $\mathrm{R}$ proteins through direct protein-protein interactions (Dodds et al. 2006). In contrast, many effectors of plant pathogenic bacteria are recognized indirectly by their corresponding $\mathrm{R}$ proteins following modification of a virulence target (Chisholm et al. 2006; Innes 2004; Schneider 2002). The indirect recognition model implies that the identification of effectors not only provides insight into their roles as triggers of plant innate immunity but also contributes to our understanding of virulence and pathogenicity mechanisms. Indeed, the recent characterization of plant pathogen effectors and their targets revealed several biochemical mechanisms for host target modification (Chisholm et al. 2006; Desveaux et al. 2006). For example, target modification may involve an enzymatic activity, such as proteolytic cleavage and phosphorylation. The Pseudomonas syringae effectors AvrRpt2, AvrRpm1, and AvrB mediate such enzymatic activities to modify their host plant target RIN4. AvrRpt2 cleaves RIN4 proteolytically, which in the presence of the R protein RPS2, results in activation of plant innate immunity (Axtell et al. 2003). Both AvrRpm1 and AvrB mediate phosphorylation of RIN4, resulting in activation of another R protein, RPM1 (Mackey et al. 2002). Alternatively, plant pathogen effectors may alter host cell processes by interacting with plant targets that function as enzymes. One example is Cladosporium fulvum Avr2, which targets and inhibits the plant protease Rcr3, which, in the presence of the Cf-2 R protein, leads to resistance (Rooney et al. 2005). In summary, the current view is that functional characterization of effectors from bacterial as well as eukaryotic plant pathogens, promises to enhance our knowledge of the biochemical mechanisms of host cell reprogramming during the infection process (Kamoun 2007).

Structure-function analyses of plant pathogen effectors revealed either a tight link or a distinct structural basis for the virulence and avirulence activities. For some effectors that dis- 
play enzymatic activities, avirulence and virulence functions are tightly linked at the structural level. Mutations in the catalytic triad of AvrRpt 2 not only abolished avirulence activity but also processing and elimination of the plant target RIN4 (Axtell et al. 2003). Random mutagenesis of AvrB identified mutants that showed loss of both avirulence and virulence activities in soybean and Arabidopsis (Ong and Innes 2006). Desveaux and associates (2007) showed that AvrB mediates effector activities not only through interacting with RIN4 but also via phosphorylation and ADP binding. Mutations that abolished these activities also resulted in loss of RPM1 activation, demonstrating that the virulence and avirulence functions of the AvrB effector are linked. In sharp contrast to these examples, structure-function studies of $P$. syringae AvrPtoB indicated that distinct structural features are required for avirulence and celldeath suppression activities (Abramovitch et al. 2003). AvrPtoB is a modular protein, with the $\mathrm{N}$-terminal region required for recognition by tomato Pto and the $\mathrm{C}$-terminal region required for suppression of programmed cell death (PCD) (Abramovitch et al. 2003). The three-dimensional structure of the C-terminal AvrPtoB region revealed similarity to an E3 ubiquitin ligase (Janjusevic et al. 2006). Mutations affecting AvrPtoB ubiquitin ligase activity abolished suppression of PCD in tomato but not recognition by Pto (Janjusevic et al. 2006). Therefore, in contrast to AvrRpt 2 and AvrB, virulence and avirulence functions of AvrPtoB can be uncoupled and assigned to distinct protein domains.

The oomycetes comprise highly developed plant pathogens that secrete diverse classes of effectors, including the ubiquitous RXLR effectors that are translocated inside host cells (Kamoun 2006, 2007; Morgan and Kamoun 2007). The conserved RXLR motif in this class of effectors is functionally similar to a host cell-targeting signal of malaria parasites (Bhattacharjee et al. 2006; Haldar et al. 2006; Kamoun 2006) and is required for translocation into host plant cells (Dou et al. 2008b; Whisson et al. 2007). One of the best-studied oomycete RXLR effectors to date is Phytophthora infestans AVR3a, which confers avirulence on potato plants carrying the $R 3 a$ gene (Armstrong et al. 2005). Two alleles of Avr3a encode secreted proteins AVR $3 \mathrm{a}^{\mathrm{K} 80 / 1103}$ (referred to as AVR3 $\mathrm{a}^{\mathrm{KI}}$ in this paper) and AVR $3 \mathrm{a}^{\mathrm{E} 80 / \mathrm{M} 103}$ (AVR3 $\mathrm{a}^{\mathrm{EM}}$ ) that differ in only three amino acids, two of which are in the mature protein. AVR $3 \mathrm{a}^{\mathrm{KI}}$ but not AVR3 $\mathrm{a}^{\mathrm{EM}}$ is recognized specifically in the plant cytosol by the nucleotide binding and leucine-rich repeat $\mathrm{R}$ protein R3a (Armstrong et al. 2005). In addition to its avirulence activity, AVR $3 \mathrm{a}^{\mathrm{KI}}$ suppresses the cell death induced by INF1 elicitin, another secreted protein of $P$. infestans (Bos et al. 2006). Elicitins such as INF1 form a structurally conserved protein family in oomycetes that trigger defenses in a variety of solanaceous plants and have features of PAMPs (Nürnberger and Brunner 2002; Vleeshouwers et al. 2006). In contrast to AVR $3 \mathrm{a}^{\mathrm{KI}}$, no strong cell-death suppression activity has been observed for AVR $3 a^{\mathrm{EM}}$. However, AVR $3 \mathrm{a}^{\mathrm{EM}}$ can weakly suppress INF1 cell death at early timepoints after agroinfiltration compared with control treatments (Bos et al. 2006). Similar to other oomycete effectors, AVR3a is a modular protein with its $\mathrm{N}$-terminal domain encompassing the signal peptide and conserved RXLR region involved in secretion and host targeting and its C-terminal domain sufficient for the effector activities (Bos et al. 2006; Whisson et al. 2007). Within the C-terminal domain both AVR3a polymorphic residues at position 80 and 103 contribute to the effector activities of $\mathrm{AVR} 3 \mathrm{a}^{\mathrm{KI}}$, although to different degrees (Bos et al. 2006). While the K80 residue is critical for R3a activation regardless of the polymorphism at position 103, mutation of either K80 to E or I103 to M result in a significant loss of cell-death suppression. Therefore, both polymorphic residues are critical for cell-death suppression but do not contribute to the same extent to R3a activation (Bos et al. 2006).

Considering that AVR3a is the only filamentous plant pathogen effector known to not only trigger $R$ gene-mediated hypersensitivity but also suppress cell death induced by another pathogen molecule, we investigated the structural requirements for these activities. We utilized saturated high-throughput screens of AVR3a mutants expressed in Nicotiana benthamiana to identify amino acids important for recognition by $\mathrm{R} 3 \mathrm{a}$ and cell-death suppression and to determine whether these two activities can be uncoupled at the structural level. Most importantly, we identified AVR3a mutants that gain the ability to activate R3a but not to suppress cell death, suggesting that distinct amino acids condition these activities. Overall, our data point to a model in which R3a-mediated recognition of AVR3a most likely involves the interaction with one or more host proteins rather than detection through enzymatic activity.

\section{RESULTS}

High-throughput mutant screens of AVR3a activity.

We developed a strategy for high-throughput mutant screens for AVR3a activation of R3a (Fig. 1). First, we generated multiple independent mutant libraries of $\mathrm{AVR} 3 \mathrm{a}^{\mathrm{KI}}$ and $\mathrm{AVR} 3 \mathrm{a}^{\mathrm{EM}}$, using a PCR-based random mutagenesis of the $88 \mathrm{C}$-terminal amino acids that are sufficient for the effector activity of AVR3a (Bos et al. 2006). The mutants were cloned in the Potato virus $X$ (PVX) binary expression vector pGR106, which allows sensitive and high-throughput in planta assays by woundinoculation (agroinfection) (Huitema et al. 2004). N. benthamiana leaves, transiently expressing R3a, were wound-inoculated with Agrobacterium tumefaciens strains carrying the AVR3a mutants. Cell-death responses surrounding the wounding sites, indicative of R3a hypersensitivity, were scored starting from 5 days postinoculation (dpi). The main advantage of the PVX-based inoculation assays is that mutants are screened in a high-throughput manner enabling rapid processing of hundreds of clones. In particular, no liquid cultures are required for inoculum preparation, reducing handling time and errors. Cell-death responses around the wounding sites are easily visible and highly consistent among replications (Fig. 1B and data not shown). Finally, the wound inoculation agroinfection assays are more sensitive than agroinfiltration assays (J. I. B. Bos and S. Kamoun, unpublished). Using this approach (Fig. 1), we assayed over 11,000 AVR3a mutants: approximately 4,500 for AVR $3 \mathrm{a}^{\mathrm{KI}}$ and approximately 6,580 for AVR $3 \mathrm{a}^{\mathrm{EM}}$. Since the effector domain used for mutagenesis consists of 88 amino acids encoded by 264 nucleotides, we expect that these mutant collections would cover mutations in all codons in excess, therefore enabling saturated screens.

\section{AVR3a ${ }^{\mathrm{KI}}$ R3a loss-of-function mutants.}

We screened more than 4,500 AVR $3 \mathrm{a}^{\mathrm{KI}}$ mutant clones for loss of induction of R3a hypersensitivity. We sequenced all candidates showing a loss-of-function phenotype and eliminated clones that carry frameshift mutations, could not be unambiguously sequenced, or were not confirmed in repeat wound-inoculation experiments. In the end, we identified 13 clones with R3a-loss of function (R3a-lof) phenotypes (Supplementary Table 1 ). These 13 clones contain one to five aminoacid changes per insert, with an average of 2.6 per clone. Within this set of 13 clones, five contain unique single mutations, and eight contain two or more mutations resulting in amino-acid substitutions. Two of the eight clones with multiple mutations contain amino-acid substitutions identical to substitutions identified in single-mutation clones, indicating some level of redundancy. Follow-up agroinfiltration assays confirmed loss of 
AVR $3 \mathrm{a}^{\mathrm{KI}}$ activity for four of the five single-mutation clones L78W, L91P, W105R, and L119P (Fig. 2A). Three of these four mutants contain substitutions by proline or tryptophan residues that potentially disrupt protein structure.

To determine whether the R3a-lof mutations affect conserved residues, we performed amino-acid sequence alignments in ClustalW of six different AVR3a homologs from $P$. infestans, $P$. sojae, and P. capsici (Fig. 2B). Three of the four R3a-lof mutations, L78W, W105R, and L119P, affected amino-acid residues conserved among the AVR3a homologs. Prediction of solvent accessibility of AVR3a residues using Jnet software (Cuff et al. 1999) showed that three of the four mutated amino-acid residues, L91P, W105R, and L119P, were likely buried, with less than $25 \%$ relative solvent accessibility, indicating that they are deeply embedded in the structure of the protein.

To determine whether the loss of R3a activation by the AVR $3 \mathrm{a}^{\mathrm{KI}}$ mutants correlates with a loss of cell-death suppression, we assayed the four single R3a-lof mutants (i.e., L78W, L91P, W105R, and L119P) for suppression of INF1 cell death. All four mutants failed to suppress INF1 cell death, indicating that the mutations not only affected avirulence activity but also cell-death suppression (Fig. 2C). In these experiments, we also included as negative controls two frameshift mutants with a truncated open reading frame and the double-substitution nonfunctional mutant L91P/V75G. As expected, these three clones failed to activate R3a and suppress INF1 cell death.

To determine the extent to which the mutations affect protein stability, we expressed the four AVR3 $\mathrm{a}^{\mathrm{KI}} \mathrm{R} 3 \mathrm{a}$-lof mutants in $N$. benthamiana by agroinfiltration and performed Western blot analysis on leaf extracts. All four mutant proteins accumulated at lower levels, as compared with $\mathrm{AVR} 3 \mathrm{a}^{\mathrm{KI}}$ and $\mathrm{AVR} 3 \mathrm{a}^{\mathrm{EM}}$ (Fig. 3). While L91P, W105R, and L119P did not accumulate to detectable levels, a faint signal was obtained for L78W (Fig. 3 ). This experiment suggests that the loss of activity of the four AVR3 $\mathrm{a}^{\mathrm{KI}}$ mutants is likely the result of reduced protein stability in planta. This is consistent with a higher percentage of infiltration sites with INF1 HR in cell-death suppression assays for these AVR $3 \mathrm{a}^{\mathrm{KI}}$ mutants compared with the AVR $3 \mathrm{a}^{\mathrm{EM}}$ control, which may have residual cell-death suppression activity.

In summary, the R3a-lof mutant screen was not particularly informative regarding the key structural components mediating the induction of R3a resistance. First, a relatively small num-

Fig. 1. Overview of the high-throughput screening strategy of AVR3a mutants. A, i) Polymerase chain reaction-based mutagenesis of the C-terminal effector domain of AVR3a was performed and included the addition of an epitope tag for follow-up protein detection experiments. ii) Amplicons were cloned in the Potato virus X (PVX)-based expression vector pGR106. Constructs were transformed in Agrobacterium tumefaciens GV3101 and transformants were picked for storage and assays. iii) A. tumefaciens strains carrying AVR3a constructs were grown on LB agar plates supplemented with antibiotics in preparation for the functional assays. iv) A. tumefaciens strains expressing R3a were infiltrated into Nicotiana benthamiana leaves. v) One day after infiltration of the R3a construct, leaves were challenged by wound-inoculation with $A$. tumefaciens strains carrying the mutant AVR3a constructs. vi) AVR3a inserts were sequenced from the clones recovered in the screens. vii) Mutants of interest were validated by coexpression with R3a using agroinfiltration. viii) Mutants of interest were assayed for suppression of INF1 cell death by coexpression with INF1 by agroinfiltration. B, Examples of phenotypes observed in wound-inoculation sites on leaves transiently expressing R3a challenged with A. tumefaciens strains carrying AVR3a constructs. C, Examples of phenotypes observed in infiltration sites coexpressing AVR3a with R3a or INF1 upon agroinfiltration in $N$. benthamiana leaves. KI indicates AVR $3 \mathrm{a}^{\mathrm{KI}}$ and EM indicates $\mathrm{AVR} 3 \mathrm{a}^{\mathrm{EM}}$. ber of mutants were recovered (4 of 4,500). Second, the four identified mutations affect the stability of the $\mathrm{AVR} 3 \mathrm{a}^{\mathrm{KI}}$ protein resulting in inactive mutant proteins.

\section{AVR3a ${ }^{\text {EM }}$ R3a-gain of function mutants.}

We screened more than 6,580 AVR $3 \mathrm{a}^{\mathrm{EM}}$ mutant clones for gain of activation of R3a hypersensitivity. After eliminating clones that carry frameshift mutations, could not be unambiguously sequenced, or were not confirmed in validation wound assays, 136 mutants were retained as consistently showing an R3a gain-of-function (R3a-gof) phenotype (Supplementary Table 2). These clones carried one to five amino-acid substitutions with an average of 1.76 changes per clone. Sequence analyses revealed a high level of redundancy among the recovered mutants. Sixty-one clones corresponding to 24 nonredundant mutants were determined to contain a single substitution in 15 different amino-acid sites. Three mutations, S123R, $\mathrm{S} 123 \mathrm{~N}$, and S123G, obtained in double mutants were recreated as single-mutation clones bringing the total number of nonre-

A

\section{i) Mutagenic PCR}

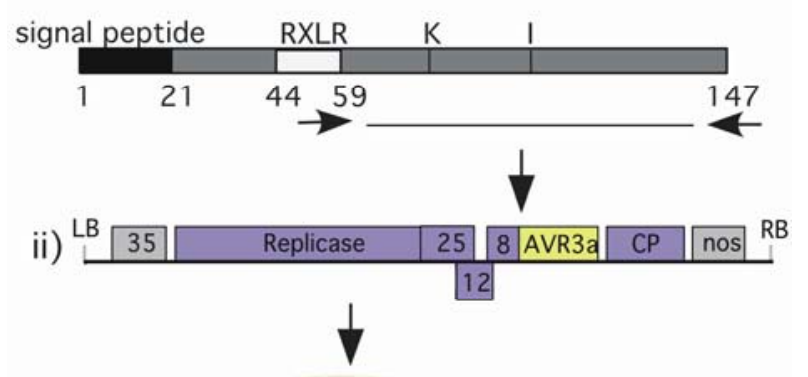

iii)

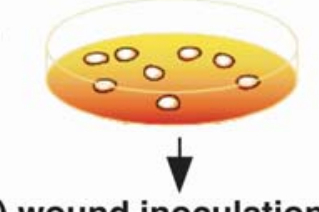

iv) express $R 3 a$

v) wound inoculation

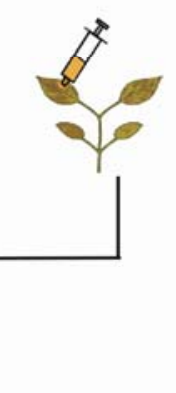

vii) validation viii) $C D$ suppression

vi) sequence analyses, database storage
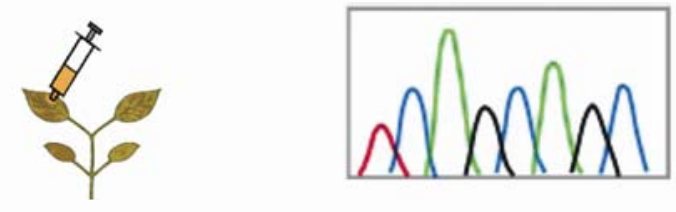

B
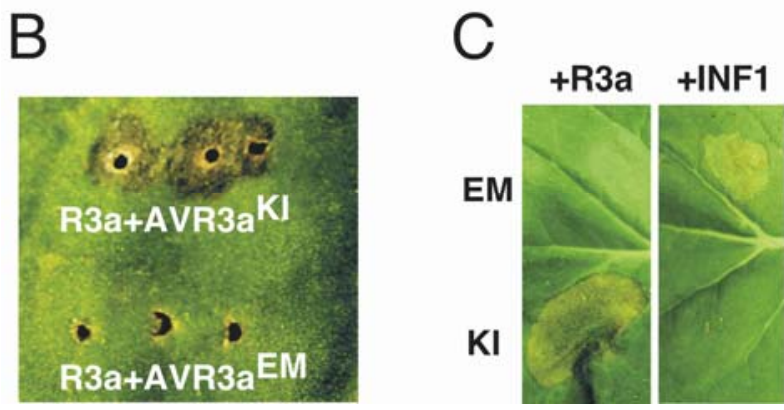
A
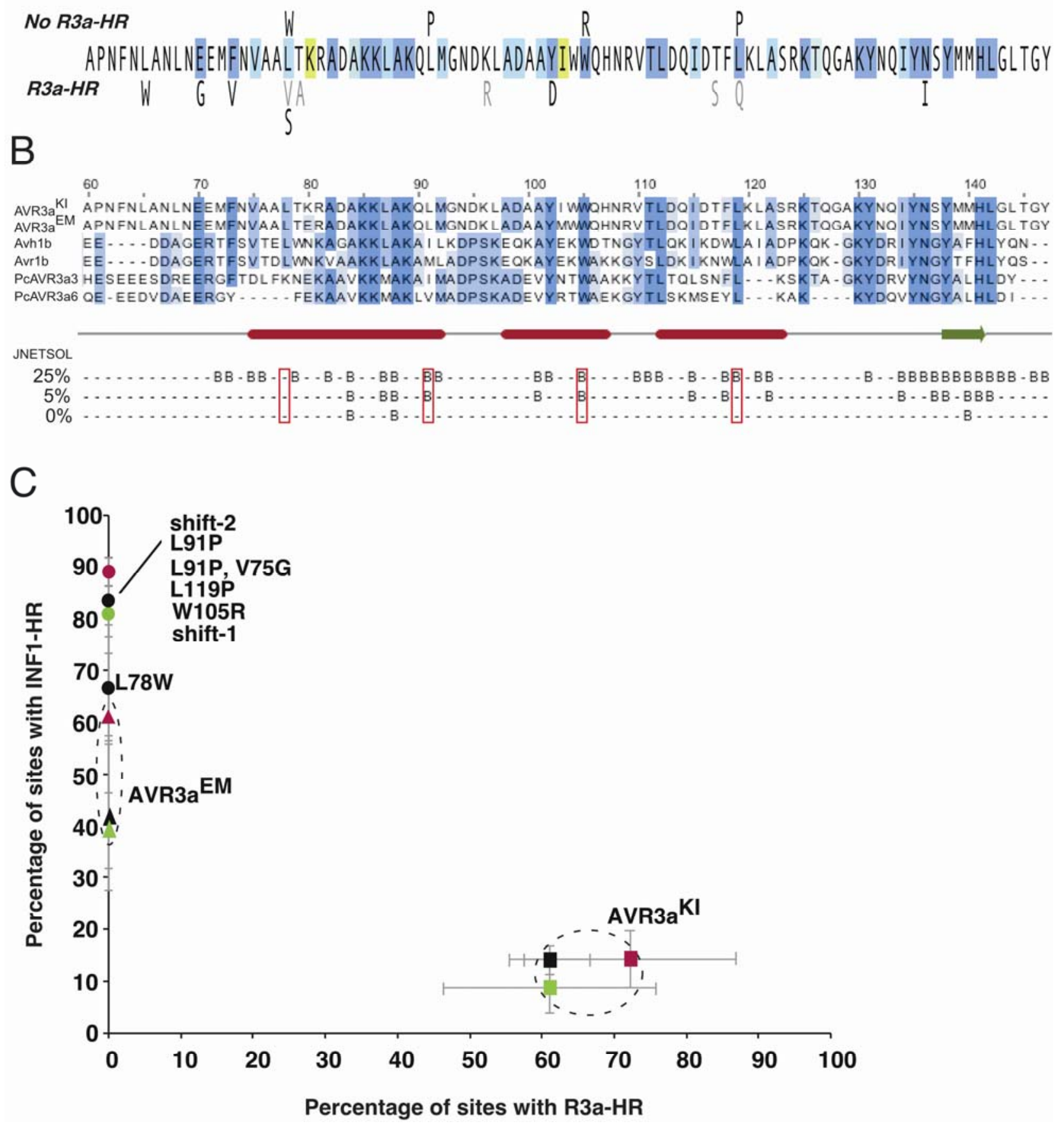

Fig. 2. AVR $3 \mathrm{a}^{\mathrm{KI}} \mathrm{R} 3 \mathrm{a}-\mathrm{loss}$ of function (R3a-lof) mutants. A, Amino-acids sequence of AVR $3 \mathrm{a}^{\mathrm{KI}}$ highlighting the R3a-lof mutants. Substitutions resulting in R3a-lof in both Nicotiana benthamiana wound-inoculation and agroinfiltration assays with R3a are shown above the sequence. The two polymorphic residues between AVR3 $\mathrm{a}^{\mathrm{KI}}$ and $\mathrm{AVR} 3 \mathrm{a}^{\mathrm{EM}}$ are indicated in yellow. Amino acids below AVR $3 \mathrm{a}^{\mathrm{KI}}$ sequence indicate substitutions that were sequenced but did not affect R3a activation. Amino-acid substitutions indicated in black were identified in single mutation clones and the ones in gray originated from double mutants. Conserved amino acids, based on alignment of Phytophthora infestans, P. sojae, and P. capsici AVR3a homologs shown in panel B, are shaded blue. Darker blue indicates higher level of identity. B, Amino-acid alignment of AVR3a ${ }^{\mathrm{KI}}$ (GenBank accession AAN31507) and AVR3a ${ }^{\mathrm{EM}}$ (GenBank accession CAI72345) from $P$. infestans with Avr1b (genbank accession AAM20937) and Avh1b (GenBank accession AAM20941) from P. sojae and two AVR3a homologs from P. capsici (P. capsici draft genome available from the Joint Genome Institute. Below the alignment, a predicted secondary structure and solvent accessibility predictions $(25,5$, and $0 \%$ relative accessibility levels) are indicated as determined by Jnet secondary structure prediction. Red tubes indicate helices, and green arrows indicate sheets. The letter B indicates buried residues. A red box indicates predicted buried residues that were mutated in the AVR3a R3a-lof mutants. C, AVR3 ${ }^{\mathrm{KI}}$ R3a-lof mutants do not suppress INF1 cell death. AVR3 $\mathrm{a}^{\mathrm{KI}}, \mathrm{AVR} 3 \mathrm{a}^{\mathrm{EM}}$, the four single substitution mutants (L78W, L91P, W105R, and L119P), two frameshift mutants (shift-1 and shift-2), and a double substitution mutant L91P/V75G were coexpressed with either R3a or INF1 by agroinfiltration to assay effector activities. We infiltrated 12 sites per mutant per assay in three replicated experiments, and scored the number of infiltration sites showing either the R3a hypersensitive response (HR) or INF1 cell death. The $x$ axis corresponds to the average percentage of infiltration sites with R3a HR, and the $y$ axis, the percentage of infiltration sites with INF1 cell death. Error bars indicate standard error of the means $(n \geq 10$ sites per clone). AVR $3 \mathrm{a}^{\mathrm{KI}}$ control treatments from the three independent experiments are indicated as squares and $\mathrm{AVR} 3 \mathrm{a}^{\mathrm{EM}}$ as triangles. The complete set of mutants assayed was split into different groups for side-by-side assays with controls. Mutants and controls within each group are represented by identical colors. Dotted ellipses indicate locations of the means of the control treatments without encompassing the error bars. 
dundant single-site mutants to 27 (Fig. 4A). Among the remaining 75 clones with two or more mutations, 63 carry amino-acid substitutions identical to substitutions observed in the single mutation clones. All 27 mutants were subjected to agroinfiltration assays to confirm the R3a-gof phenotype using a different assay. Nineteen of these 27 clones induced R3a hypersensitivity by agroinfiltration consistent with independent observations in our laboratory that wound-inoculation is a more sensitive assay than agroinfiltration (Fig. 4B). These results suggest that the R3a-gof mutants have varying levels of activities and that the 19 mutants confirmed by agroinfiltration have higher $\mathrm{R} 3 \mathrm{a}$ induction activity than the remaining eight mutants.

The 27 R3a-gof mutations affect 15 different sites out of 88 mutated AVR3a ${ }^{\mathrm{EM}}$ amino acids (Fig. 4A). Analyses of the sampling curves for the number of gain-of-function mutations and the number of distinct amino acids mutated indicate that $\geq 90 \%$ of all possible mutations leading to a gain-of-function of AVR3 $\mathrm{a}^{\mathrm{EM}}$ were recovered (Supplementary Fig. 1). Mutations to valine, glycine, and alanine were recovered for residue E80, which is polymorphic between AVR $3 \mathrm{a}^{\mathrm{EM}}$ and AVR $3 \mathrm{a}^{\mathrm{KI}}$, confirming that it significantly contributes to R3a activation (Armstrong et al. 2005; Bos et al. 2006). Strikingly, 14 out of the 15 R3a-gof sites are predicted to be surface- exposed based on Jnet software (Cuff et al. 1999) (Fig. 4C). Of these 14 potential surface residues, 10 correspond to charged amino acids, and four of the five remaining residues were mutated to a charged residue in at least one occasion (Fig. 4A). Finally, only four out of the 15 mutated sites in the R3a-gof mutants (i.e., K89, D99, K125, and K130) were found to be conserved among the AVR3a homologs (Fig. 4C).

The R3a-gof mutants did not induce cell death in the absence of R3a on $N$. benthamiana (data not shown). Also, none of the approximately 6,580 screened AVR $3 \mathrm{a}^{\mathrm{EM}}$ clones induced visible responses upon wound-inoculation on tobacco plants, indicating that the gain of HR-inducing activity is dependent on R3a (data not shown).

To determine the extent to which the R3a-gof mutants are affected in INF1 cell-death suppression, we quantitatively assayed the 19 R3a-gof mutants confirmed by agroinfiltration (Fig. 4D). First, we observed that the levels of HR induced by the different mutants varied significantly from AVR $3 \mathrm{a}^{\mathrm{EM}}$ and AVR $3 a^{\mathrm{KI}}$. Fourteen of the 19 mutants showed activation levels significantly greater than AVR3 $\mathrm{a}^{\mathrm{EM}}$, based on the Dunnett's multiple comparison test (family error rate $P<0.05$, individual error rate $P<0.002$; Supplementary Table 3), while five mutants did not, due to low frequencies of R3a activation. Of these, 11 (E80A, E80G, E80V, R81G, D83G, K96M, D99E, D99V, S123C, Q127H, and K130E) showed R3a activation levels similar to AVR $3 \mathrm{a}^{\mathrm{KI}}$, while the remaining three mutants activated R3a at significantly (family error rate $P<0.05$, individual error rate $P<0.002$ ) lower levels compared with $\mathrm{AVR} \mathrm{a}^{\mathrm{KI}}$ (Fig 4D). Similar quantitative assays indicated that 18 of the 19 mutants did not significantly suppress INF1 cell death as strongly as AVR3a ${ }^{\mathrm{KI}}$ (Fig. 4D; Supplementary Table 4). Using Dunnett's multiple pairwise comparison test, the response of only one mutant, S123C, did not differ from AVR $3 \mathrm{a}^{\mathrm{KI}}$ while, at the same time, differing from that of $\mathrm{AVR}^{\mathrm{EM}}$ (family error rate $P<0.05$, individual error rate $P<$ 0.002).

We assessed the protein stability of a set of AVR $3 \mathrm{a}^{\mathrm{EM}} \mathrm{R} 3 \mathrm{a}-$ gof mutants in $N$. benthamiana, using Western blot analysis. As shown previously (Bos et al. 2006), AVR $3 \mathrm{a}^{\mathrm{KI}}$ and $\mathrm{AVR} 3 \mathrm{a}^{\mathrm{EM}}$ were equally stable in planta and could be detected at similar levels (Supplementary Fig. 2). In addition, the AVR $3 \mathrm{a}^{\mathrm{EM}} \mathrm{R} 3 \mathrm{a}-$ gof mutants were at least as stable in planta as the wild-type proteins. Thus, the differences in R3a activation and cell-death suppression activity are not due to differences in proteins stability and likely reflect differences in biochemical activities of the proteins.

\section{AVR3a mutants with substitutions}

at the polymorphic glutamate/lysine residue at position 80 .

The finding that three AVR3 $\mathrm{a}^{\mathrm{EM}} \mathrm{R} 3 \mathrm{a}$-gof clones are mutated in the polymorphic E80 residue confirmed our earlier observation that position 80 is critical for R3a activation (Armstrong et al. 2005; Bos et al. 2006) and prompted us to evaluate the impact of all 20 amino-acid variations at this position on R3a activation and cell-death suppression. We used a PCR-based mutagenesis approach to generate all possible amino-acid variations at position 80 in the $A V R 3 \mathrm{a}^{\mathrm{EM}}$ background $\left(A V R 3 a^{\mathrm{E} 80 \mathrm{X} / \mathrm{M} 103}\right.$ ) and AVR3 $\mathrm{a}^{\mathrm{KI}}$ background (AVR3a ${ }^{\mathrm{K} 80 \mathrm{X} / 1103}$ ). Wound-inoculation assays on $N$. benthamiana leaves expressing R3a revealed that 14 of the 20 amino acids at position 80 mediated R3a activation for both AVR3a isoforms (Fig. 5A and B). The remaining six that did not result in R3a-gof phenotypes correspond to all amino acids with aromatic (F, Y, W), negatively charged (E, D), or cyclic (P) side chains (Fig. 5A and $\mathrm{B}$ ).

We used agroinfiltration to coexpress the complete set of 20 AVR $3 \mathrm{a}^{\mathrm{E} 80 \mathrm{X} / \mathrm{M} 103}$ mutants with R3a or INF1 in $N$. benthamiana to quantify R3a activation and cell-death suppression (Fig. 5C). The 14 mutants that induced R3a hypersensitivity in the wound-inoculation assays also activated $\mathrm{R} 3 \mathrm{a}$ in agroinfiltration assays, although at levels ranging from 30 to $90 \%$ of the inoculated sites (Fig. 5C). Statistical comparisons using the Dunnett's test indicated that nine mutants (E80C, E80H, E80I, E80Q, E80N, E80R, E80S, E80T, E80V) induced R3a hypersensitivity at levels comparable to the wild-type AVR $3 \mathrm{a}^{\mathrm{KI}}$ but different from AVR $3 \mathrm{a}^{\mathrm{EM}}$ (family error rate $P<0.05$, individual error rate $P<0.003$ ) (Fig. 5C; Supplementary Table 5). Similar quantitative assays indicated that none of the 20 AVR $3 \mathrm{a}^{\mathrm{E} 80 \mathrm{X} / \mathrm{M} 103}$ mutants suppressed INF1 cell death as strongly as $\mathrm{AVR} 3 \mathrm{a}^{\mathrm{KI}}$, though this pattern was not statistically significant for mutants E80G, E80L, and E80Y (Fig. 5C; Supplementary Table 6). These three mutants displayed cell-death suppression phenotypes that were similar to AVR $3 \mathrm{a}^{\mathrm{KI}}$ but differed from AVR3a ${ }^{\mathrm{EM}}$ (family error rate $P<0.05$, individual error rate $P<$ 0.003) (Fig. 5C). In summary, stringent statistical analyses suggest that none of the 20 AVR $3 \mathrm{a}^{\mathrm{E} 80 \mathrm{X} / \mathrm{M} 103}$ mutants suppress INF1 cell death as strongly as AVR $3 \mathrm{a}^{\mathrm{KI}}$ but weak support was obtained for three of the 20 mutants.

To determine the extent to which the same 20 amino-acid variations in the AVR $3 \mathrm{a}^{\mathrm{KI}}$ background affect INF1 cell-death suppression, we coexpressed the complete set of AVR $3 \mathrm{a}^{\mathrm{K} 80 \mathrm{X} / 103}$

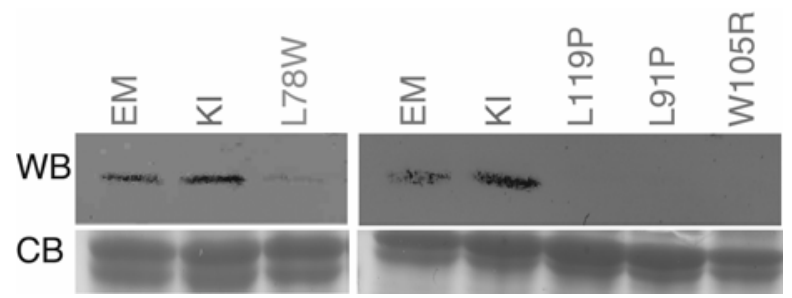

Fig. 3. The AVR $3 \mathrm{a}^{\mathrm{KI}}$ R3a-loss-of-function (R3a-lof) mutants are unstable in planta. FLAG antisera Western blots (WB) were performed on total protein extracts of leaves of Nicotiana benthamiana following agroinfiltration with constructs expressing various FLAG-AVR3a mutants. An approximately $15-\mathrm{kDa}$ protein band representing recombinant AVR3a was present in total extracts of the infiltrated $N$. benthamiana leaves. To test for equal loading, protein samples were separated using sodium dodecyl sulfatepolyacrylamide gel electrophoresis for Coomassie blue (CB) staining. AVR3 ${ }^{\mathrm{KI}} \mathrm{R} 3 \mathrm{a}$-lof mutants and the AVR3 $\mathrm{a}^{\mathrm{EM}}$ control are indicated in green font and the AVR $3 \mathrm{a}^{\mathrm{KI}}$ control in red. 

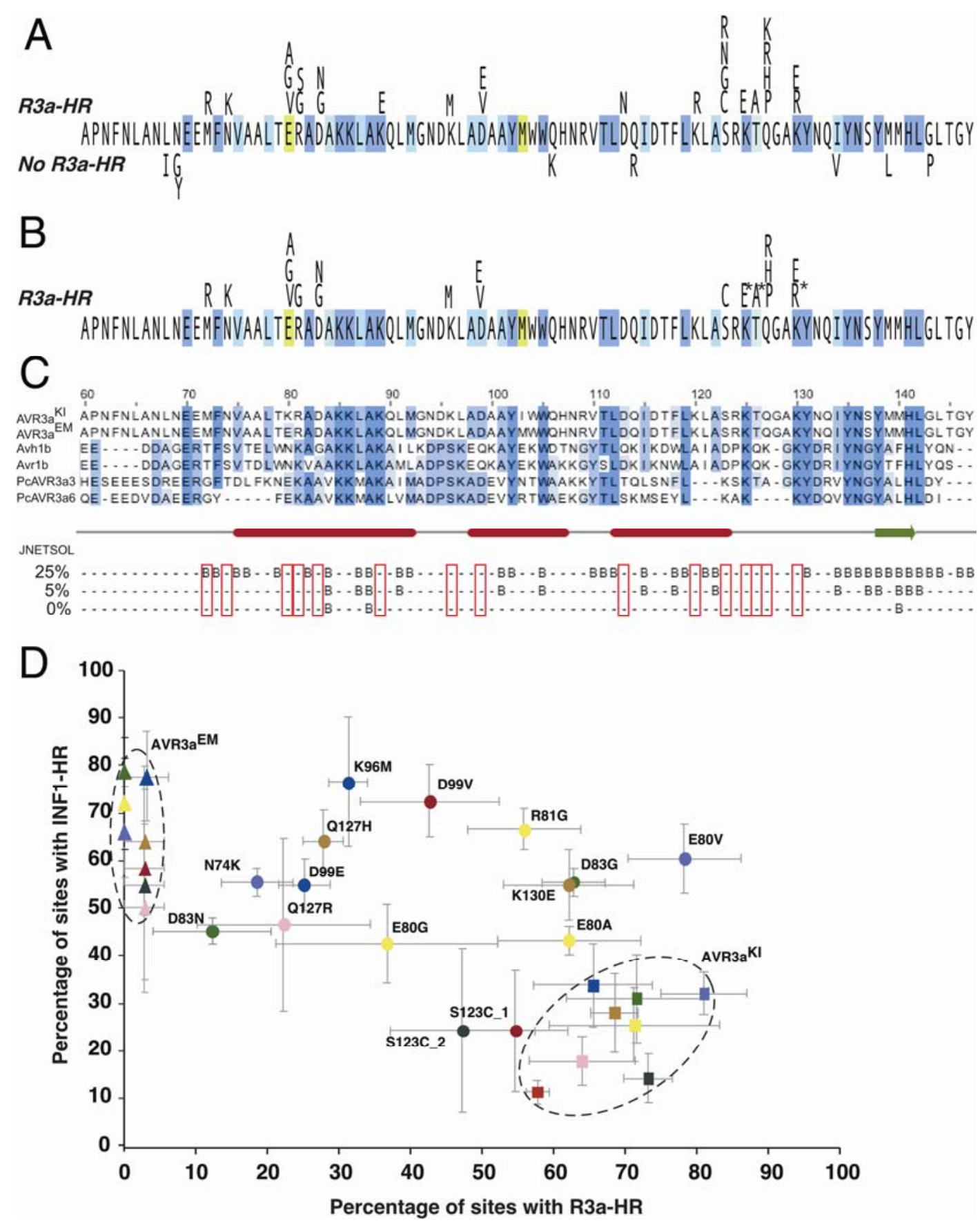

Fig. 4. AVR $3 \mathrm{a}^{\mathrm{EM}} \mathrm{R} 3 \mathrm{a}$-gain of function (R3a-gof) mutants. A, Amino acid sequences of AVR $3 \mathrm{a}^{\mathrm{EM}}$ highlighting the gain of function mutants for R3a activation identified in wound-inoculation assays on Nicotiana benthamiana leaves transiently expressing R3a. Amino acids above the AVR $3 \mathrm{a}^{\mathrm{EM}}$ sequence indicate substitutions resulting in R3a-gof. The two polymorphic residues between AVR3a ${ }^{\mathrm{KI}}$ and AVR3a ${ }^{\mathrm{EM}}$ are indicated in yellow. Amino acids below the AVR3a sequence indicate substitutions that were sequenced but did not result in gain of function. Conserved amino acids, based on the alignment of Phytophthora infestans, P. sojae, and P. capsici AVR3a homologs shown in panel C, are shaded in blue. Darker blue indicates higher level of similarity. B, Amino-acid sequences of AVR $3 \mathrm{a}^{\mathrm{EM}}$ showing the gain of function mutants for R3a activation that were validated in agroinfiltration assays on Nicotiana benthamiana leaves transiently expressing R3a. Asterisks indicate mutants that induced R3a hypersensitive response (HR) in agroinfiltrations only in the background of library I but not library II (Panel A). C, Amino-acid alignment of AVR3a ${ }^{\mathrm{KI}}$ (genbank accession AAN31507) and AVR3a ${ }^{\mathrm{EM}}$ (genbank accession CAI72345) from P. infestans with Avr1b (genbank accession AAM20937) and Avh1b (genbank accession AAM20941) from P. sojae and two AVR3a homologs from P. capsici (P. capsici draft genome available from the Joint Genome Institute. Below the alignment, the secondary structure and solvent accessibility predictions (25, 5, and $0 \%$ relative accessibility levels) as determined by Jnet secondary structure prediction are shown. Red tubes indicate helices and green arrows indicate sheets. The letter B indicates buried residues. A red box indicates predicted buried residues that were mutated in the AVR3a-gof mutants. D, Activation of $\mathrm{R} 3 \mathrm{a}$ and suppression of INF1 cell death by AVR3 $\mathrm{a}^{\mathrm{EM}} \mathrm{R} 3 \mathrm{a}$-gof mutants. The mutants identified in screens for R3a activation were coexpressed with either R3a or INF1 by agroinfiltration to assay for effector activities. We infiltrated 12 sites per mutant per assay in three replicated experiments and scored the number of infiltration sites showing either R3a HR or INF1 cell death. On the $x$ axis, we plotted the average percentage of infiltration sites with R3a HR, and on the $y$ axis, the percentage of infiltration sites with INF1 cell death. Error bars indicate standard error of the means $\left(n \geq 10\right.$ sites per clone). AVR3a ${ }^{\mathrm{KI}}$ control treatments are indicated as squares and AVR $3 \mathrm{a}^{\mathrm{EM}}$ controls as triangles. The complete set of mutants was split into different groups for side-by-side assays with controls. Mutants and controls within each group are shown in identical colors. Dotted ellipses indicate locations of the means of the control treatments without encompassing the error bars. For clarity, only the 14 mutants that showed significantly stronger R3a induction activity than AVR3a ${ }^{\mathrm{EM}}$, based on the Dunnett's multiple comparison test $(P<0.05)$, are shown and mutants with activities lower than D83N were not included in the graph. Two independent clones of the S123C mutant (S123C_1 and S123C_2) were included. 

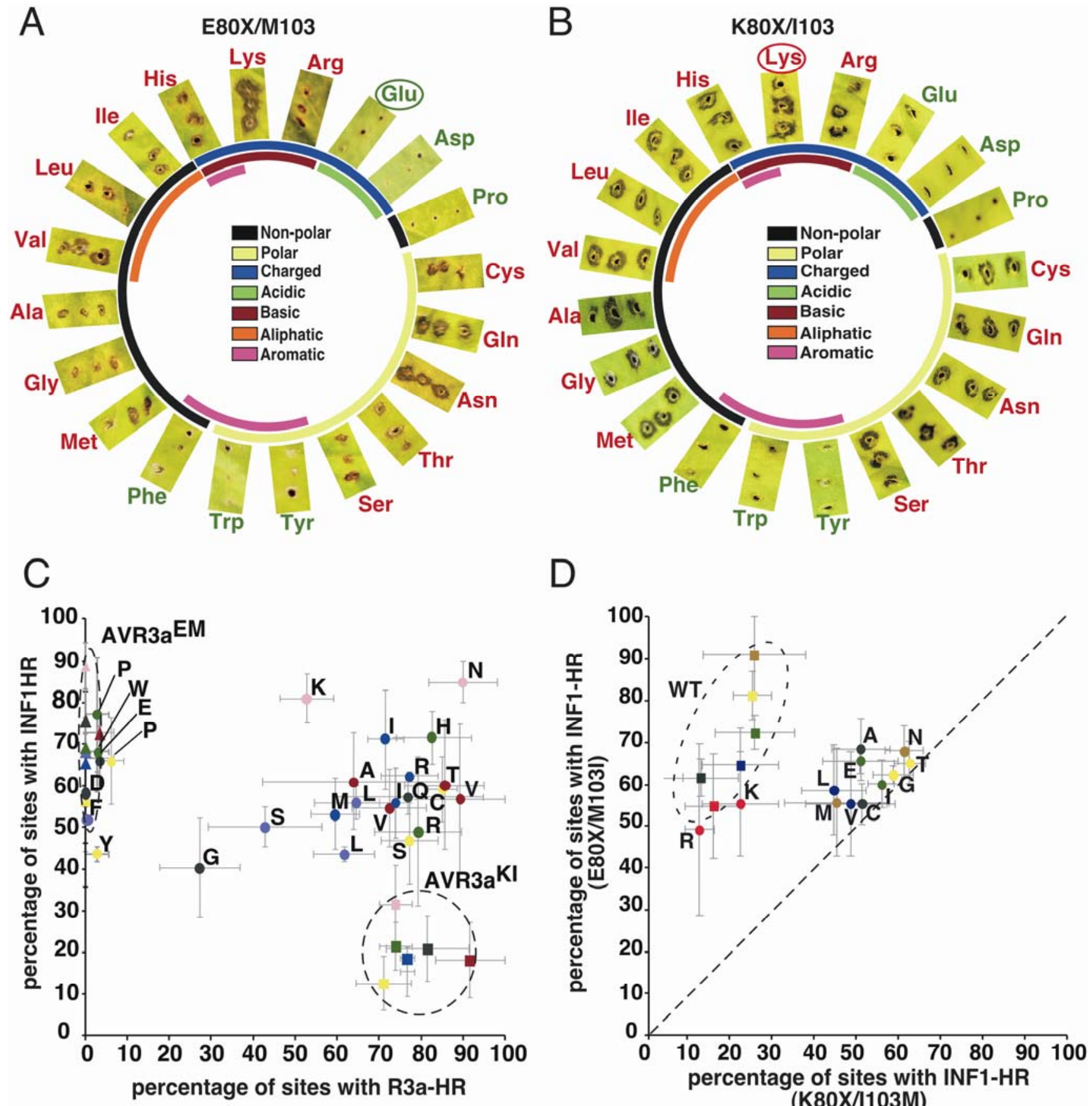

(K80X/l103M)

Fig. 5. AVR3a mutants with all possible amino-acid substitutions at the polymorphic glutamate/lysine residue in position 80 . A, The majority of the aminoacid substitutions in AVR3 $\mathrm{a}^{\mathrm{E} 80 \mathrm{X} / \mathrm{M} 103}$ resulted in gain of function in R3a coexpression assays. Mutants were assayed for activation of R3a in wound-inoculation assays. Substitutions with the amino acids indicated in red font resulted in R3a gain of function, whereas amino acids in green font did not. Partial circles with different colors represent features of side-chain amino-acid residues, as described in the center. The glutamate 80 residue that naturally occurs in AVR $3 \mathrm{a}^{\mathrm{EM}}$ is circled. B, The majority of the amino-acid substitutions in AVR $3 \mathrm{a}^{\mathrm{K} 80 \mathrm{X} / 103}$ did not affect R3a activation. Mutants were assayed for activation of R3a in wound-inoculation assays. Substitutions with amino acids indicated in red resulted in gain of function, whereas amino acids in green font did not. Partial circles with different colors represent features of side-chain amino-acid residues. The lysine 80 residue that naturally occurs in AVR3 ${ }^{\mathrm{KI}}$ is circled. C, Activation of R3a and suppression of INF1 cell death by the 20 AVR3 $\mathrm{a}^{\mathrm{E} 80 \mathrm{X} / \mathrm{M} 103}$ mutants. AVR3 $\mathrm{a}^{\mathrm{E} 80 \mathrm{X} / \mathrm{M} 103}$ mutants were coexpressed with either R3a or INF1 by agroinfiltration. We infiltrated 12 sites per mutant per assay in three replicated experiments and scored the number of infiltration sites showing either R3a hypersensitive response (HR) or INF1 cell death. On the $x$ axis, we plotted the average percentage of infiltration sites with R3a hypersensitivity, and on the $y$ axis, the percentage of infiltration sites with INF1 cell death. AVR $3 \mathrm{a}^{\mathrm{KI}}$ control treatments are indicated as squares and AVR $3 \mathrm{a}^{\mathrm{EM}}$ controls as triangles. The complete set of mutants was split into different groups for side-by-side assays with controls. Mutants and controls within each group are represented by identical colors. Dotted ellipses indicate locations of the means of the control treatments without encompassing the error bars. D, Cell-death suppression by select AVR3 $\mathrm{a}^{\mathrm{K} 80 \mathrm{X} / 1103}$ and AVR3 $\mathrm{a}^{\mathrm{E} 80 \mathrm{X} / \mathrm{M} 103}$ mutants in side-by-side assays. We infiltrated 10 to 12 sites per mutant per assay in three replicated experiments and scored the number of infiltration sites showing INF1 cell death. On the $x$ axis, we plotted the average percentages of infiltration sites showing INF1 cell death upon coexpression with AVR3 $\mathrm{a}^{\mathrm{K} 80 \mathrm{X} / 1103}$ mutants, and on the $y$ axis, the percentages of sites with INF1 cell death upon coexpression with AVR $3 \mathrm{a}^{\mathrm{E} 80 \mathrm{X} / \mathrm{M} 103}$. As a control, we plotted percentages of infiltration sites with INF1 cell death upon coexpression with AVR3 ${ }^{\mathrm{KI}}$ and AVR3a ${ }^{\mathrm{EM}}$ on the $x$ and $y$ axes respectively (marked as WT). The control data points are represented by squares and indicated by a dotted ellipse. The select set of mutants was split into different groups for side-by-side assays with controls. Mutants and controls within each group are represented by identical colors. The dotted diagonal line represents the expected data points if mutants in both the AVR $3 \mathrm{a}^{\mathrm{KI}}$ and $\mathrm{AVR} 3 \mathrm{a}^{\mathrm{EM}}$ background suppressed INF1 cell death in a 1:1 ratio. 
mutants with INF1 and quantified percentages of infiltration sites with INF1 cell death (data not shown). Based on this, we selected nine of the 20 mutants with the lowest percentages of sites with INF1 cell death (15 to $40 \%$ ), one mutant with a high percentage of sites with INF1 cell death $(51 \%)$, and the two mutants with glutamate and lysine amino-acid residues at position 80 for side-by-side cell-death suppression assays in the AVR $3 \mathrm{a}^{\mathrm{K} 80 \mathrm{X} / 1103}$ and AVR $3 \mathrm{a}^{\mathrm{E} 80 \mathrm{X} / \mathrm{M} 103}$ backgrounds. None of the 12 mutants in the AVR $3 \mathrm{a}^{\mathrm{E} 80 \mathrm{X} / \mathrm{M} 103}$ background, including AVR $3 \mathrm{a}^{\mathrm{E} 80 \mathrm{~K} / \mathrm{M} 103}$, suppressed INF1 at levels similar to that of AVR $3 \mathrm{a}^{\mathrm{KI}}$ (Fig. 5D). However, one of the $12 \mathrm{AVR} \mathrm{a}^{\mathrm{K} 80 \mathrm{X} / 1103} \mathrm{mu}-$ tants, AVR3a $\mathrm{a}^{\mathrm{K} 80 \mathrm{R} / 103}$, suppressed INF1 at a level similar to that of AVR $3 \mathrm{a}^{\mathrm{KI}}\left(13 \%\right.$ for AVR $3 \mathrm{a}^{\mathrm{K} 80 \mathrm{R} / 1103}$ versus $16 \%$ for $\left.\mathrm{AVR} 3 \mathrm{a}^{\mathrm{KI}}\right)$ (Fig. 5D). Chi-square analyses support that the cell-death suppression frequency of AVR $3 \mathrm{a}^{\mathrm{K} 80 \mathrm{R} / 103}$ significantly differed from AVR3a ${ }^{\mathrm{EM}}$ but not from AVR3a ${ }^{\mathrm{KI}}(P<0.026$ in two of three replications for AVR $3 \mathrm{a}^{\mathrm{K} 80 \mathrm{R} / 1103}$ compared with AVR $3 \mathrm{a}^{\mathrm{EM}}$, $P<0.074$ in two out of three replications for AVR $3 \mathrm{a}^{\mathrm{KI}}$ compared with AVR $3 \mathrm{a}^{\mathrm{EM}}$, and $P>0.61$ in three replications for AVR $3 a^{\mathrm{K} 80 \mathrm{R} / 103}$ compared with AVR $3 \mathrm{a}^{\mathrm{KI}}$ ). We confirmed by Western blot analysis that differences in activities between select mutants, AVR $3 \mathrm{a}^{\mathrm{KI}}$ and AVR $3 \mathrm{a}^{\mathrm{EM}}$ were not due to differences in protein stability. Our data suggests that substitution of lysine 80 of $A V R 3 a^{\mathrm{KI}}$ by another positively charged residue, arginine, generated a mutant that retains full cell-death suppression activity.

Tyrosine 147 is required

for cell-death suppression but not R3a activation.

We noticed that addition of epitope tags to the C-terminus of AVR3a interferes with cell-death suppression but not R3a activation (data not shown). This prompted us to perform targeted
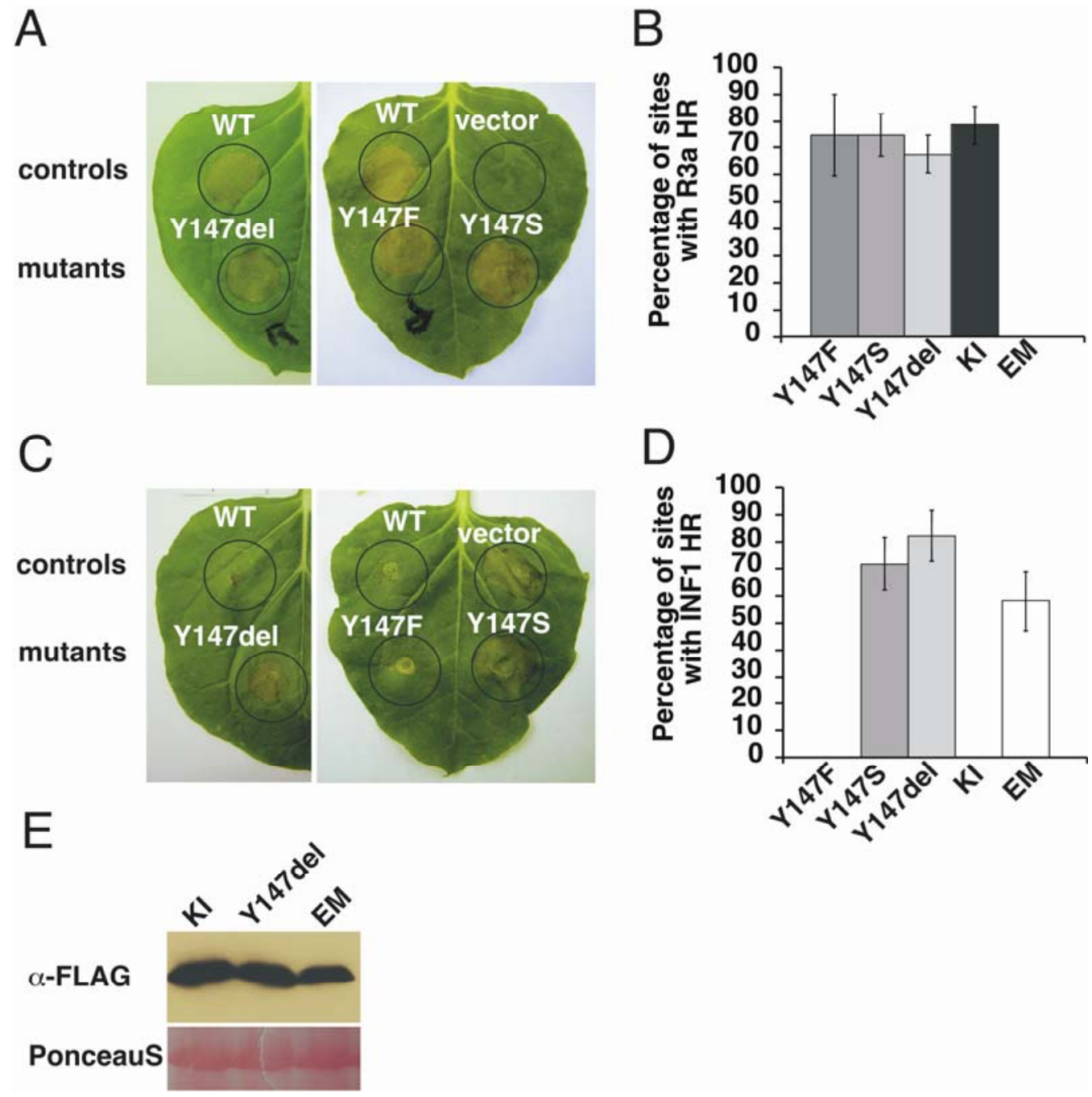

D

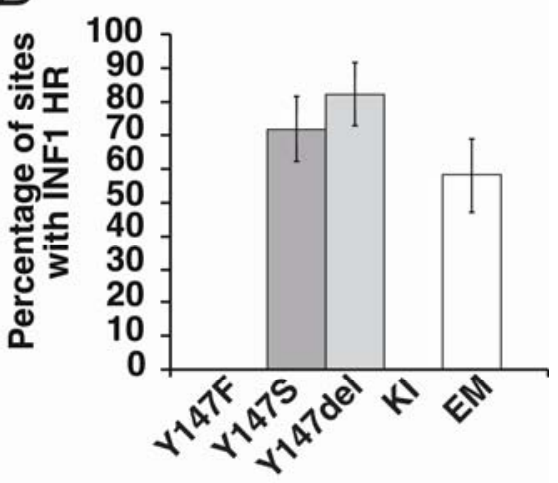

Fig. 6. Tyrosine 147 of AVR3a is required for cell-death suppression and is dispensable for induction of R3a hypersensitivity. Y147_del indicates the AVR $3 \mathrm{a}^{\mathrm{KI}}$ mutant with a deletion of the tyrosine residue at position 147 . Y $147 \mathrm{~F}$ and Y $147 \mathrm{~S}$ indicate AVR3a ${ }^{\mathrm{KI}}$ mutants with tyrosine $147 \overline{7}$ substituted with phenylalanine or serine respectively. WT indicates wild-type AVR $3 \mathrm{a}^{\mathrm{KI}}$ (60-147). A, Induction of the R3a hypersensitive response (HR) by AVR3a ${ }^{\mathrm{KI}}$ mutants with mutations of the tyrosine residue at position 147. AVR3a wild-type and mutants were assayed by coexpression with R3a, using agroinfiltration of Nicotiana benthamiana leaves. B, Percentages of R3a HR induced by different AVR3a constructs. Average percentages of infiltration sites showing R3a HR were calculated and plotted on the $y$ axis. Error bars indicate standard error of the means $(n \geq 9$ sites) per clone. Responses were scored 5 days after infiltration. Percentages of sites with R3a HR for the vector control typically are $0 \%$. C, Suppression of INF1 elicitin cell death by AVR3a ${ }^{\mathrm{KI}}$ mutants mutated in the tyrosine residue at position 147. AVR3a wild-type and mutants were assayed for cell-death suppression by coexpression with INF1, using agroinfiltration of Nicotiana benthamiana leaves. D, Percentages of sites with INF1 cell death upon coexpression of INF1 with different AVR3a constructs. Average percentages of infiltration sites showing INF1 HR were calculated and plotted on the $y$ axis. Error bars indicate standard error of the means $(n \geq 9$ sites per clone). Responses were scored 4 days after infiltration. Percentages of sites with INF1 HR for the vector control typically are 80 to $100 \%$. E, The AVR3a tyrosine 147 (Y147) deletion mutant is stable in planta. Western blot analyses of N. benthamiana leaf tissues expressing FLAG-tagged AVR3a ${ }^{\mathrm{KI}}$, AVR3 $\mathrm{a}^{\mathrm{EM}}$, and the AVR $3 \mathrm{a}^{\mathrm{KI}}$ Y147 deletion mutant 5 days after agroinfiltration. The upper panel shows the Western blot incubated with FLAG antibody, and the lower panel shows Ponceau S staining of the Western blot as a loading control. 
mutagenesis of the conserved $\mathrm{C}$-terminal tyrosine residue at position 147 of $\mathrm{AVR} 3 \mathrm{a}^{\mathrm{KI}}$ and to assay the corresponding constructs for effector activities. The C-terminal tyrosine (Y147) residue was deleted $\left(\mathrm{AVR} 3 \mathrm{a}^{\mathrm{KI} / \mathrm{Y} 147 \mathrm{del})}\right.$ ) and substituted with serine $\left(\mathrm{AVR} 3 \mathrm{a}^{\mathrm{KI} / \mathrm{Y} 147 \mathrm{~S}}\right.$ ) or phenylalanine $\left(\mathrm{AVR} 3 \mathrm{a}^{\mathrm{KI} / \mathrm{Y} 147 \mathrm{~F}}\right)$. All three Y147 mutants retained the ability to activate R3a upon coexpression by agroinfiltration (Fig. 6A and B). However, coexpression of the AVR $3 \mathrm{a}^{\mathrm{KI}}$ Y 147 mutants with INF1 indicated that AVR3 $\mathrm{a}^{\mathrm{KI} / \mathrm{Y} 147 \mathrm{~F}}$ suppresses INF1 cell death, while AVR $3 \mathrm{a}^{\mathrm{K} / \mathrm{Y} 147 \mathrm{del}}$ and AVR3a ${ }^{\mathrm{KI} / \mathrm{Y} 147 \mathrm{~S}}$ do not (Fig. 6C and D).

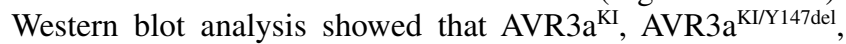
and AVR $3 \mathrm{a}^{\mathrm{EM}}$ proteins were equally stable in planta, indicating that the observed differences in activity were not due to altered protein stability (Fig. 6E). This data points to Y147 as a critical AVR $3 \mathrm{a}^{\mathrm{KI}}$ residue for cell-death suppression and suggests that different amino acids of AVR3a are required for R3a activation and cell-death suppression.

\section{DISCUSSION}

Host-translocated effector proteins of plant pathogens display dual activities, namely suppression and elicitation of plant innate immunity, depending on the genotype of the host plant. Structure-function analyses are critical for dissecting the structural basis of effector activities and unraveling the biochemical mechanisms underlying pathogenicity and host resistance. In this study, we performed extensive structure-function analyses of the RXLR effector AVR3a of P. infestans to determine the structural requirements for R3a activation and INF1 cell-death suppression. We performed high-throughput random screens as well as targeted mutagenesis of key residues to identify AVR3a mutants with altered activities. Numerous mutants that gained the ability to activate R3a but not to suppress cell death were recovered leading to our main finding that distinct amino-acids condition the two effector activities of AVR3a.

We took advantage of the "toothpick" wounding agroinfection method (Huitema et al. 2004) to implement a screening strategy that enabled saturation mutagenesis of the $88 \mathrm{C}$-terminal amino acids of AVR3a. In total, over 11,000 random mutants were screened. A remarkable level of redundancy was noted among the 136 mutants recovered in the R3a-gof screen of AVR $3 \mathrm{a}^{\mathrm{EM}}$, confirming that the screen is saturating. In contrast, no redundant clones were recovered among the 13 informative R3a-lof mutants of AVR3a ${ }^{\mathrm{KI}}$, suggesting that this screen was not saturating and that R3a-lof mutants are recovered at low frequency. This is explained to some extent by the smaller number of mutants tested in the loss-of-function compared with the gain-of-function screen (approximately 4,500 versus approximately 6,500). In addition, many loss-of-function mutants were not useful, consisting of frameshift and other null mutations, making it more challenging to recover informative positive mutants.

The R3a-gof mutations of AVR3 $\mathrm{a}^{\mathrm{EM}}$ consist overwhelmingly of residues that are polymorphic between AVR3a homologs and are predicted to localize on the surface of AVR3a (14 of 15 ) in contrast to the R3a-lof mutations, which mainly affect conserved and buried residues that reduce in planta stability of mutant AVR3a proteins. Dou and associates (2008a) recently described mutants of Avr1b, a homolog of AVR3a, with reduced suppression of the cell death induced by the mouse Bax protein and in some cases Rps $1 \mathrm{~b}$ activation but did not test these mutant forms for altered stability. Because these Avr1b mutations localize to conserved and buried residues in a region known as the W-motif, the possibility that the Dou and associates (2008a) loss-of-function mutants of Avrlb have reduced stability in plant cells needs to be seriously considered. We interpret our finding that the informative mutant residues are predicted to be exposed as suggesting that recognition of AVR3a by R3a likely involves interactions between AVR3a and a host protein rather than through an enzymatic activity of AVR3a. Our results are, therefore, incompatible with a model in which $\mathrm{AVR} 3 \mathrm{a}^{\mathrm{EM}}$ is an inactive enzyme isoform of AVR $3 \mathrm{a}^{\mathrm{KI}}$, since it is unlikely that so many independent second site mutations in AVR $3 \mathrm{a}^{\mathrm{EM}}$ would restore enzymatic activity. In addition, R3alof mutations that result in an inactive AVR $3 \mathrm{a}^{\mathrm{KI}}$ enzyme would have been recovered in larger frequency than observed. Thus, it is most likely that $\mathrm{AVR} 3 \mathrm{a}^{\mathrm{KI}}$ is recognized by $\mathrm{R} 3 \mathrm{a}$ through binding one or more host proteins, similar to several other plant pathogen effectors that are recognized indirectly (van der Hoorn and Kamoun 2008). Alterations of surface-exposed residues in AVR $3 \mathrm{a}^{\mathrm{EM}}$ by second site mutations would then reestablish interactions with this target, resulting in R3a activation. The observation that 14 of the 15 mutated residues in the AVR3a ${ }^{\mathrm{EM}}$ R3a-gof mutants involve charged amino acids is consistent with an altered binding state model and is reminiscent of the type of mutations determined in the $M$. lini AvrL567 effector to alter binding and recognition by flax $\mathrm{R}$ proteins (Dodds et al. 2006). Despite the conclusion spelled out above regarding a potential mechanism of AVR3a recognition by R3a, our results cannot rule out that an enzymatic activity of AVR3a is involved in cell-death suppression.

Another possible mode of recognition is that both AVR $3 \mathrm{a}^{\mathrm{KI}}$ and AVR3 $\mathrm{a}^{\mathrm{EM}}$ elicit R3a hypersensitivity but that AVR $3 \mathrm{a}^{\mathrm{EM}}$ is also a suppressor of R3a hypersensitivity. This scenario is consistent with the high frequency R3a-gof mutants recovered for AVR $3 a^{\mathrm{EM}}$, since such mutants would have resulted from a loss of suppression of R3a hypersensitivity. However, this unusual model is unlikely because it is inconsistent with the observation that coexpression of the two AVR3a proteins does not affect the ability of AVR3a $\mathrm{a}^{\mathrm{KI}}$ to activate R3a (J. I. B. Bos and $\mathrm{S}$. Kamoun, unpublished), suggesting that AVR3 $\mathrm{a}^{\mathrm{EM}}$ does not suppress R3a hypersensitivity in trans. This is consistent with the observation that $P$. infestans strains that are heterozygote at the Avr $3 a$ locus and produce both isoforms are avirulent on $R 3 a$ potato (Armstrong et al. 2005). In addition, most AVR3a ${ }^{\mathrm{EM}}$ R3a-gof mutations apparently implicate surfaceexposed residues, suggesting that they do not impact the protein tertiary structure, as is the case for the AVR $3 \mathrm{a}^{\mathrm{KI}} \mathrm{R} 3 \mathrm{a}-\mathrm{lof}$ mutants.

The avirulence and cell-death suppression activities of AVR3a can be uncoupled at the structural level. Thus AVR3a contrasts with several bacterial effectors, such as $P$. syringae AvrB. Mutant screens of AvrB revealed that the avirulence and virulence activities are coupled and involve the same residues (Ong and Innes 2006). AvrB appears to carry its virulence activity by binding and mediating the phosphorylation of RIN4. More recently, Desveaux and associates (2007) showed that AvrB residues that are directly implicated in the AvrB-RIN4 interaction are also required for activation of RPM1. Thus, unlike AVR3a, AvrB appears to bind a host protein, RIN4, which mediates not only the effector virulence activity but also the activation of RPM1, leading to effector-triggered immunity. Our results suggest that AVR3a is more similar to AvrPtoB, in which the avirulence and virulence activities can be uncoupled (Abramovitch et al. 2003; Janjusevic et al. 2006). In AvrPtoB, the two activities are carried out by distinct domains within the protein. This is unlikely to be the case for AVR3a since the effector region is relatively small (less than 80 residues) and the R3a-gof mutations are spread out over most of this sequence.

Our finding that the cell-death suppression and R3a elicitation activities of AVR3a can be uncoupled at the structural level leads to several alternative models, which are summarized in Figure 7. These models evoke either a direct or indirect activation of $\mathrm{R} 3 \mathrm{a}$. To date. evidence for a direct interaction 
between AVR3a and R3a has not been obtained using yeasttwo-hybrid assays and in planta pulldowns (M. Armstrong and P. Birch, personal communication; J. I. B. Bos and S. Kamoun, unpublished). However, these negative findings do not rule out the possibility of transient binding of AVR3a to R3a and experimental evidence for direct interaction between Avr and R proteins remains scarce in the literature (Dodds et al. 2006). Alternatively, a host target might be required for activation of

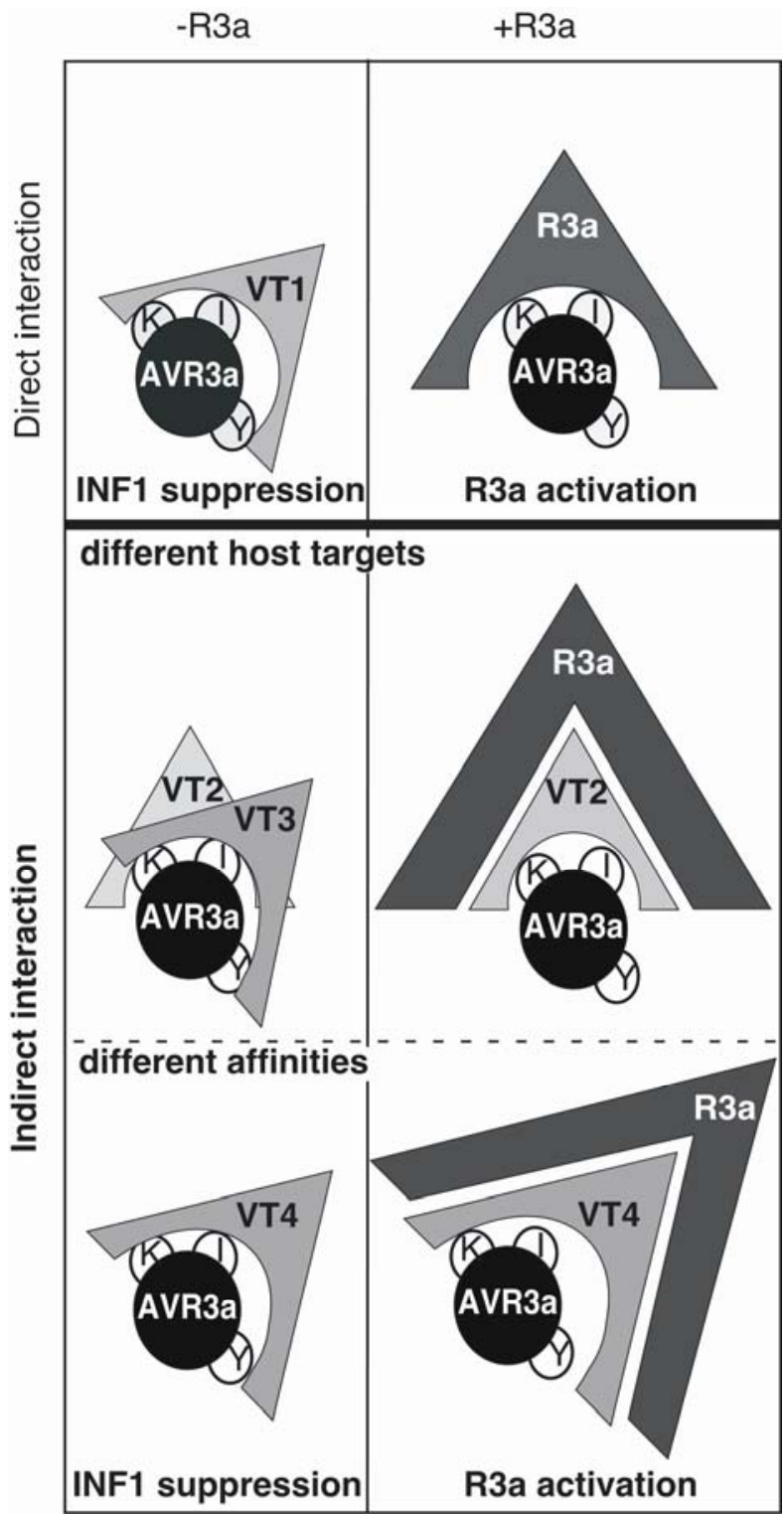

Fig. 7. Simplified model for AVR3a activities based on either a direct interaction between AVR3a and R3a or an indirect interaction. In the direct interaction model, AVR3a binds directly to R3a, and in the absence of its cognate $\mathrm{R}$ protein, it binds to its virulence target (VT1). In the indirect interaction model, multiple options are possible for AVR3a-R3a and AVR3a-VT interactions. One possibility is that distinct regions of AVR3a target multiple host proteins VT2 and VT3. Binding to VT2 requires the polymorphic K80 and I103 residues, whereas VT3 binding, in addition to these residues, requires the Y147 residue. R3a detects binding to VT2 and, therefore, is dependent on the K80 and I103 residues. INF1 cell-death suppression requires binding to VT3 and, therefore, is dependent on the K80, I103, and Y147 residues. Alternatively, AVR3a binds at least one target, VT4, through amino-acid residues K80, I103, and Y147. R3a detects binding of AVR3a to VT4. Binding affinity of AVR3a to VT4 based on the two amino-acid residues K80 and I103 is sufficient for recognition by R3a. However, INF1 cell-death suppression requires a binding affinity of AVR3a to VT4 based on the three amino-acid residues K80, I103, and Y147.
R3a (Fig. 7). Our data also suggest that one or more host targets of AVR3a are required for cell-death suppression (Fig. 7). The cell-death suppression activity of AVR3a could result from interaction with multiple host targets with different binding requirements or from differences in binding affinities to one host target. It is now evident that many plant pathogen effectors have multiple host targets (Hogenhout et al. 2008; van der Hoorn and Kamoun 2008). Interaction between a given effector and these host protein targets can be beneficial for the pathogen, have negative consequences, or have neutral effects on the pathosystem (Hogenhout et al. 2008; van der Hoorn and Kamoun 2008). In case AVR3a targets multiple host proteins, it will be important to discriminate between the "operative target" (Fig. 7, VT3 and VT4) that would be required for mediating the cell-death suppression activity of AVR3a and the host protein required for activation of $\mathrm{R} 3 \mathrm{a}$, which could potentially be a "decoy" (Fig.7, VT2) with no effect on host immunity in the absence of R3a (van der Hoorn and Kamoun 2008).

We confirmed our previous findings that amino acid K80 is important for R3a activation regardless of the polymorphism at residue 103 but that both $\mathrm{K} 80$ and $\mathrm{I} 103$ contribute to cell-death suppression activity (Bos et al. 2006). Mutations of AVR3a residue 80 to all possible amino acids confirmed that this site is important for both the virulence and avirulence activities (Fig. 5). The 20 amino-acid variations had the same effects on $\mathrm{R} 3 \mathrm{a}$ activation in both the AVR $3 \mathrm{a}^{\mathrm{KI}}$ or AVR $3 \mathrm{a}^{\mathrm{EM}}$ backgrounds, confirming the key role of position 80 in $\mathrm{R} 3 \mathrm{a}$ recognition. Most amino acids at this position, with the notable exception of acidic and aromatic residues, did not affect activation of $\mathrm{R} 3 \mathrm{a}$. We interpret this finding as suggesting that the AVR3a binding site in the host target can accommodate most residues except acidic and aromatic amino acids. However, it remains possible that residues with aromatic side chains affect stability of AVR3a resulting in loss of R3a activation.

None of the amino-acid variations in the AVR $3 \mathrm{a}^{\mathrm{EM}}$ background, including AVR $3 \mathrm{a}^{\mathrm{KM}}$ and AVR $3 \mathrm{a}^{\mathrm{RM}}$, suppressed INF1 hypersensitivity at levels similar to that of AVR $3 \mathrm{a}^{\mathrm{KI}}$. We also discovered that the C-terminal tyrosine residue (Y147) is critical for cell-death suppression but dispensable for R3a activation (Fig. 6). Several AVR3a homologs from various Phytophthora species carry a C-terminal tyrosine but do not suppress INF1 cell death (J. I. B. Bos and S. Kamoun, unpublished), indicating that this residue is not the only determinant of celldeath suppression. Substitution of Y147 with a phenylalanine, which, like tyrosine, contains an aromatic side-chain, did not affect the cell-death suppression activity. Possibly, the aromatic side chain of the C-terminal residue of AVR3a participates in binding to a virulence target to mediate cell-death suppression (Fig. 7).

Models of plant-pathogen coevolution predict that an AVR3a isoform that suppresses cell death but yet circumvents recognition by R3a would be the most advantageous for P. infestans. Interestingly, we failed to identify such a form of AVR3a, despite the large number of mutants tested. Our initial highthroughput mutant screens were focused on R3a activation and not cell-death suppression activity, which may explain why we failed to identify such mutants. On the other hand, only a few mutations in AVR $3 \mathrm{a}^{\mathrm{KI}}$ result in loss of R3a activation without an effect on protein stability, suggesting that AVR3a R3a-lof mutants that retain the ability to suppress INF1 cell death may not be easily recovered. In spite of our finding that distinct AVR3a residues mediate virulence and avirulence activities, AVR3a mutants that fail to activate R3a were not able to suppress cell death at levels similar to that of AVR $3 \mathrm{a}^{\mathrm{KI}}$. Structural requirements for cell-death suppression appear to be highly specific and include the occurrence of a positively charged amino acid at position 80 of $\mathrm{AVR} 3 \mathrm{a}^{\mathrm{KI}}$. For instance, only 
AVR $3 a^{\mathrm{KI}}$ and AVR $3 \mathrm{a}^{\mathrm{RI}}$ strongly suppressed INF1 cell death, but both proteins equally activate R3a hypersensitivity. This suggests that perhaps AVR $3 \mathrm{a}^{\mathrm{KI}}$ is a form of AVR3a with a relatively exceptional virulence activity that is, therefore, maintained in populations of $P$. infestans despite being recognized by R3a. Such examples of balancing selection have been previously evoked to account for the ancient nature of some Avr-R gene pairs in plant-pathogen interactions (van der Hoorn et al. 2002). Interestingly, AVR $3 \mathrm{a}^{\mathrm{KI}}$ was the only protein among its 17 closest homologs from three Phytophthora spp. that could suppress INF1 cell death (J. I. B. Bos and S. Kamoun, unpublished), consistent with the view that $\mathrm{AVR} 3 \mathrm{a}^{\mathrm{KI}}$ is a somewhat exceptional form of AVR3a.

INF1 and other elicitins have long been known as elicitor proteins produced by several oomycetes, such as Phytophthora and Pythium species. Initially, elicitins were thought to specifically induce defense responses in the genus Nicotiana (tobacco) among the family Solanacaeae. Recently however, it became apparent that INF1 triggers cell death and other immune responses in host Solanum plants (Vleeshouwers et al. 2006), providing support for the view that elicitins are conserved molecular patterns of oomycetes (PAMPs) that are widely perceived by plant surveillance systems (Nürnberger and Brunner 2002). In such cases, AVR3a may very well be classified as a suppressor of PAMP-triggered immunity, an activity that has been attributed to several bacterial type III secretion system effectors (Chisholm et al. 2006; Jones and Dangl 2006).

This study provides insights into the relationship between structure and function of $P$. infestans AVR3a, arguably one of the best-studied oomycete RXLR effectors. The next phase of research is to identify one or more virulence targets of AVR3a. We and collaborators are currently evaluating candidate plant proteins that emerged through yeast two-hybrid screens and in planta co-immunoprecipitation (M. Armstrong and P. Birch, personal communication; J. I. B. Bos and S. Kamoun, unpublished). The exhaustive collection of AVR3a mutants identified in this study is proving extremely useful in classifying the putative host targets and eliminating false positives. Another immediate objective is the resolution of the three-dimensional structure of AVR3a, which would help to assess the hypotheses that emerged from this study and establish whether the important residues identified here are indeed buried in the structure or surface-exposed. Ultimately, a thorough understanding of the biochemical basis of AVR3a activities would shed light on a key aspect of the interaction between the late blight pathogen $P$. infestans and its host plants potato and tomato.

\section{MATERIALS AND METHODS}

\section{Microbial strains and growth conditions.}

A. tumefaciens GV3101 and AGL0 (Hellens et al. 2000) were used in molecular cloning experiments and were routinely cultured at $28^{\circ} \mathrm{C}$ in Luria-Bertani (LB) media using appropriate antibiotics (Sambrook and Russell 2001). All bacterial DNA transformations were conducted by electroporation using standard protocols (Sambrook and Russell 2001).

\section{AVR3a mutant libraries.}

We constructed two mutant libraries using different primer combinations. Library I constructs carry epitope tags at the Cterminus. While assessing clones from this library, we realized that the C-terminal tags interfere with INF1 cell-death suppression but not R3a activation. Therefore, we made a second library (library II) with an N-terminal epitope tag. The majority of the informative positive clones that emerged from the library I screens were recloned to convert them into the library II vector background.
Random mutagenesis of AVR3a was performed using the Diversify PCR random mutagenesis kit from Clontech Laboratories, Inc. (Mountain View, CA, U.S.A.). PCR amplification was performed, with plasmids pGR106-AVR3a_K ${ }^{80} \mathbf{I}^{103}$ and pRG106-AVR3a_E ${ }^{80} \mathrm{M}^{103}$ as templates (Armstrong et al. 2005). Primers used for library I clones were AVR3a-60F (5'GCGATCGATGGCCCCAAATTTCAATTTGGCGAATCTA$3^{\prime}$ ) and AVR3a-HAHIS-Rnot (5'-GGAAGCGGCCGCTAGTG ATGGTGATGGTGATGAGCGTAATCTGGAACATCGTATG GGTAATATCCAGTGAGCCCCAGGTG-3'). This primer combination adds HA and HIS epitope tags to the $3^{\prime}$ end of AVR3a. Primers used for library II clones were AVR3a-60FL (5'-GCGA TCGATGGACTACAAGGACGACGATGACAAAGTCAAGC TTCTCGAGAATTCCGCCCCAAATTTCAAT-3') and AVR3aRnotU (5'-GCGGCGGCCGCGTTAGAATCGGATTTTCTG$\left.3^{\prime}\right)$. This combination adds a FLAG epitope tag to the $5^{\prime}$ end of AVR3a. PCR products were digested with ClaI and NotI and were ligated into the A. tumefaciens binary PVX vector pRG106 (Lu et al. 2003). Ligation mixes were directly transformed into A. tumefaciens GV3101 by electroporation. Transformants were picked into 384-well plates using a QPix colony-picking robot (Genetix, New Milton, U.K.) for preparation of freezer stocks.

Mutants of interest from library I were re-amplified using primers AVR3a-60FL and AVR3a-Rnot (5'- GCGGCGGCCG CCTAATATCCAGTGAGCCCCAGGTGCATCAGGTA-3') to remove the $3^{\prime}$ HAHIS epitope-encoding sequence and add the $3^{\prime}$ FLAG epitope-encoding sequence. Amplicons were ligated into the ClaI- and NotI-digested pGR106 vector as explained above.

\section{Targeted mutagenesis of AVR3a.}

AVR3a mutants with all 20 amino acids at position 80 were generated by overlap extension PCR. The first PCR amplification was performed with primers AVR3a-60FL and AVR3a N_R-80random (5'-AGCTTTTTGGCATCTGCTCTNNNCGT CAACGCAGC- $\left.3^{\prime}\right)$. A second PCR amplification was performed using primers AVR3a-C-F1 (5'-AGAGAGCAGATGCCAAAA AGCTAGCGAAACAGCTT-3') and AVR3a-RnotU. A third and final PCR amplification was performed on a 1:1 mix of the amplicons generated by the first and second PCR amplifications, using primers AVR3a-60FL and AVR3a-RnotU. Amplicons were ligated into the ClaI- and NotI-digested pGR106 vector and were transformed into A. tumefaciens as explained above. The inserts of 96 random colonies were sequenced and, typically, generated 17 or more of the 20 amino-acid variations. Specific primers based on AVR3a_N_R-80random were designed and used to generate clones for the missing aminoacid codons resulting in the complete set of 20 amino-acid mutants. In several cases, multiple codon variations for the same amino acid were used as controls in the functional assays.

To delete the C-terminal tyrosine residue at position 147 of the AVR $3 \mathrm{a}^{\mathrm{KI}}$ amino-acid sequence, we performed PCR amplification using the primers AVR3a_A60-F (5'-GCGATCGAT GGCCCCAAATTTCAATTTGGCGAATCTA-3') and Avr3a146R (5' - GCGGCGGCCGCCTATCCAGTGAGCCCCAGGT GCATCAGGTA-3'). For substitution of the C-terminal tyrosine residue at position 147 with phenylalanine or serine, we PCR-amplified with primers AVR3a_ $\triangle 60-\mathrm{F}$ and AVR3aRnot_YtoF (5'-GCGGCGGCCGCCTAAaATCCAGTGAGCC CCAGGTGCATCAGGTA-3') or AVR3a-Rnot_YtoS (5'-GCG GCGGCCGCCTAAGATCCAGTGAGCCCCAGGTGCATCA GGTA-3'). Amplicons were digested with ClaI and NotI and ligated into the $\mathrm{pGR} 106$ vector.

\section{PVX agroinfection and agroinfiltration assays.}

Recombinant $A$. tumefaciens strains were grown as described elsewhere (Van der Hoorn et al. 2000), except that the cultur- 
ing steps were performed in LB media supplemented with of kanamycin at $50 \mu \mathrm{g} / \mathrm{ml}$. Agroinfiltration experiments were performed on 4- to 6-week-old $N$. benthamiana plants. Plants were grown and maintained throughout the experiments in a greenhouse with an ambient temperature of 22 to $25^{\circ} \mathrm{C}$ and high light intensity.

For the high-throughput functional screens of AVR3a mutants, leaves of $N$. benthamiana were infiltrated with A. tumefaciens AGL0 carrying the pBINplus-R3a construct (Huang et al. 2005) at a final optical density at $600 \mathrm{~nm}\left(\mathrm{OD}_{600}\right)$ of $0.3 \mathrm{in}$ induction buffer $\left(10 \mathrm{mM} \mathrm{MES}, 10 \mathrm{MgCl}_{2}, 200 \mu \mathrm{M}\right.$ acetosyringone, $\mathrm{pH}=5.6$ ). One day after infiltration, leaves were challenged by wound-inoculation of AVR3a mutant clones using toothpicks. Each strain was assayed on four replicated leaves. As a control, each leaf was wound-inoculated with $A$. tumefaciens strains carrying pGR106-FLAG-AVR $3 \mathrm{a}^{\mathrm{KI}}$-60-147 and pGR106-FLAG-AVR3 $\mathrm{a}^{\mathrm{EM}}$ _60-147. Cell-death symptoms at the inoculation site were scored 7 to 10 days postinoculation (dpi).

To assays AVR3a mutant libraries on tobacco plants, AVR3a mutant clones were wound-inoculated on fully expanded leaves using a 96-well replicator (Huitema et al. 2004). Symptoms were analyzed 7 to $15 \mathrm{dpi}$.

Transient coexpression of $R 3 a$ and $A v r 3 a$ by agroinfiltration was performed as follows. A. tumefaciens strains carrying the pBINplus-R3a (Huang et al. 2005) and pGR106-AVR3a constructs were mixed in a $2: 1$ ratio in induction buffer to a final $\mathrm{OD}_{600}$ of 0.4. Similar procedures were used for the suppression assays, except that, for expression of $A v r 3 a$, the final $\mathrm{OD}_{600}$ of recombinant $A$. tumefaciens strains was 0.3 in induction buffer. The infiltration sites were challenged 1 day after infiltration with recombinant $A$. tumefaciens carrying p35-INF1 at a final $\mathrm{OD}_{600}$ of 0.3 in induction buffer. Symptom development was monitored from 3 to 8 days after infiltration.

In planta protein expression for Western blot detection of recombinant FLAG-AVR3a was performed by agroinfiltration of A. tumefaciens strains carrying the corresponding constructs at a final $\mathrm{OD}_{600}$ of 0.3 in induction buffer. Four infiltration sites per AVR3a construct were collected in three replicated experiments.

\section{Sequencing of AVR3a constructs.}

Amplification of inserts was performed using pGR106 vector-based primers. Generated amplicons were purified using Qiagen PCR purification columns (Qiagen, Valencia, CA, U.S.A.) and were sequenced using an ABI Prism 3100 analyzer. Base-calling and quality values were obtained using the Phred algorithm (Ewing and Green 1998). Sequences were analyzed using Sequencher 4.1 (Genes Code Corp, Ann Arbor, MI, U.S.A.).

\section{Statistical analysis.}

To perform the Dunnett's statistical test for differences in the means of the treatments versus the controls, we calculated the average percentages of sites with R3a-mediated cell death or INF1 cell death from three replicated experiments and performed rank transformations. Dunnett's test was performed using the Minitab statistical software package (family error rate $P<0.05)$.

\section{Western blot analyses.}

Leaf tissue was harvested $5 \mathrm{dpi}$ and protein extracts were prepared as described by Moffett and associates (2002). The presence of recombinant FLAG-AVR3a was determined by SDS-PAGE and Western blotting as described by Tian and associates (2004). Monoclonal FLAG M2 antibodies were obtained from Sigma (St. Louis).

\section{ACKNOWLEDGMENTS}

We are thankful to I. Malcuit and D. Baulcombe for providing the PVX vector, S. Huang for the R3a constructs, T. Meulia and the Molecular and Cellular Imaging Center (MCIC) at the OARDC-OSU in Wooster for use of equipment and for DNA sequencing, K. Jagger and M. Lee for technical assistance, and B. Morgan, E. Huitema, and J. Win for suggestions and comments on the manuscript. This work was supported by a National Science Foundation Plant Genome Research Program grant DBI-0211659 and the Gatsby Charitable Foundation. Salaries and research support were provided, in part, by state and federal funds appropriated to the Ohio Agricultural Research and Development Center, The Ohio State University.

\section{LITERATURE CITATIONS}

Abramovitch, R. B., Kim, Y. J., Chen, S., Dickman, M. B., and Martin, G. B. 2003. Pseudomonas type III effector AvrPtoB induces plant disease susceptibility by inhibition of host programmed cell death. EMBO (Eur. Mol. Biol. Organ.) J. 22:60-69.

Armstrong, M. R., Whisson, S. C., Pritchard, L., Bos, J. I. B., Venter, E., Avrova, A. O., Rehmany, A. P., Bohme, U., Brooks, K., Cherevach, I., Hamlin, N., White, B., Fraser, A., Lord, A., Quail, M. A., Churcher, C., Hall, N., Berriman, M., Huang, S., Kamoun, S., Beynon, J. L., and Birch, P. R. 2005. An ancestral oomycete locus contains late blight avirulence gene Avr3a, encoding a protein that is recognized in the host cytoplasm. Proc. Natl. Acad. Sci. U.S.A. 102:7766-7771.

Axtell, M. J., Chisholm, S. T., Dahlbeck, D., and Staskawicz, B. J. 2003. Genetic and molecular evidence that the Pseudomonas syringae type III effector protein AvrRpt2 is a cysteine protease. Mol. Microbiol. 49:1537-1546.

Bhattacharjee, S., Hiller, N. L., Liolios, K., Win, J., Kanneganti, T. D., Young, C., Kamoun, S., and Haldar, K. 2006. The malarial host-targeting signal is conserved in the Irish potato famine pathogen. PLoS Pathog. 2:e50. Published online.

Bos, J. I. B., Kanneganti, T. D., Young, C., Cakir, C., Huitema, E., Win, J. Armstrong, M. R., Birch, P. R., and Kamoun, S. 2006. The C-terminal half of Phytophthora infestans RXLR effector AVR3a is sufficient to trigger R3a-mediated hypersensitivity and suppress INF1-induced cell death in Nicotiana benthamiana. Plant J. 48:165-176.

Chisholm, S. T., Coaker, G., Day, B., and Staskawicz, B. J. 2006. Host-microbe interactions: Shaping the evolution of the plant immune response. Cell 124:803-814.

Cuff, J. A., and Barton, G. J. 1999. Evaluation and improvement of multiple sequence methods for protein secondary structure prediction. Proteins 34:508-519.

Dangl, J.L., and Jones, J.D. 2001. Plant pathogens and integrated defence responses to infection. Nature 411:826-833.

Desveaux, D., Singer, A. U., and Dangl, J. L. 2006. Type III effector proteins: Doppelgangers of bacterial virulence. Curr. Opin. Plant Biol. 9:376-382.

Desveaux, D., Singer, A. U., Wu, A. J., McNulty, B. C., Musselwhite, L., Nimchuk, Z., Sondek, J., and Dangl, J. L. 2007. Type III effector activation via nucleotide binding, phosphorylation, and host target interaction. PLoS Pathog. 3:e48. Published online.

Dodds, P. N., Lawrence, G. J., Catanzariti, A. M., Teh, T., Wang, C. I., Ayliffe, M. A., Kobe, B., and Ellis, J. G. 2006. Direct protein interaction underlies gene-for-gene specificity and coevolution of the flax resistance genes and flax rust avirulence genes. Proc. Natl. Acad. Sci. U.S.A. 103:8888-8893.

Dou, D., Kale, S. D., Wang, X., Chen, Y., Wang, Q., Jiang, R. H., Arredondo, F. D., Anderson, R. G., Thakur, P. B., McDowell, J. M., Wang, Y., and Tyler, B. M. 2008. Conserved C-terminal motifs required for avirulence and suppression of cell death by Phytophthora sojae effector Avr1b. Plant Cell 20:1118-11133.

Dou, D., Kale, S. D., Wang, X., Jiang, R. H., Bruce, N. A., Arredondo, F. D., Zhang, X., and Tyler, B. M. 2008. RXLR-mediated entry of Phytophthora sojae effector Avrlb into soybean cells does not require pathogen-encoded machinery. Plant Cell 20:1930-1947.

Ewing, B., and Green, P. 1998. Base-calling of automated sequencer traces using phred. II. Error probabilities. Genome Res. 8:186-194.

Haldar, K., Kamoun, S., Hiller, N. L., Bhattacharjee, S., and van Ooij, C. 2006. Common infection strategies of pathogenic eukaryotes. Nat. Rev. Microbiol. 4:922-931.

Hellens, R. P., Edwards, E. A., Leyland, N. R., Bean, S., and Mullineaux, P. M. 2000. pGreen: A versatile and flexible binary Ti vector for Agrobacterium- mediated plant transformation. Plant Mol. Biol. 42:819-832.

Hogenhout, S. A., Van der Hoorn, R. A. L., Terauchi, R. and Kamoun, S. 2008. Emerging concepts in effector biology of plant-associated organisms. Mol. Plant-Microbe Interact. 22:115-122. 
Huitema, E., Bos, J. I. B., Tian, M., Win, J., Waugh, M. E., and Kamoun, S. 2004. Linking sequence to phenotype in Phytophthora-plant interactions. Trends Microbiol. 12:193-200.

Huang, S., van der Vossen, E. A., Kuang, H., Vleeshouwers, V. G., Zhang, N., Biorm, T. J., van Eck, H. J., Baker, B., Jacobsen, E., and Visser, R. G. 2005. Comparative genomics enabled the isolation of the R3a late blight resistance gene in potato. Plant J. 42:251-261.

Innes, R. W. 2004. Guarding the goods. New insights into the central alarm system of plants. Plant Physiol. 135:695-701.

Janjusevic, R., Abramovitch, R. B., Martin, G. B., and Stebbins, C. E. 2006. A bacterial inhibitor of host programmed cell death defenses is an E3 ubiquitin ligase. Science 311:222-226.

Jones, J. D., and Dangl, J. L. 2006. The plant immune system. Nature 444:323-329.

Kamoun, S. 2006. A catalogue of the effector secretome of plant pathogenic oomycetes. Annu. Rev. Phytopathol. 44:41-60.

Kamoun, S. 2007. Groovy times: Filamentous pathogen effectors revealed. Curr. Opin. Plant Biol. 10:358-365.

Lu, R., Martin-Hernandez, A. M., Peart, J. R., Malcuit, I., and Baulcombe, D. C. 2003. Virus-induced gene silencing in plants. Methods 30:296-303.

Mackey, D., Holt, B. F., Wiig, A., and Dangl, J. L. 2002. RIN4 interacts with Pseudomonas syringae type III effector molecules and is required for RPM1-mediated resistance in Arabidopsis. Cell 108:743-754.

Martin, G. B., Bogdanove, and A. J., Sessa, G. 2003. Understanding the functions of plant disease resistance proteins. Annu. Rev. Plant Biol. 54:23-61.

Moffett, P., Farnham, G., Peart, J., and Baulcombe, D. C. 2002. Interaction between domains of a plant NBS-LRR protein in disease resistancerelated cell death. EMBO (Eur. Mol. Biol. Organ.) J. 21:4511-4519.

Morgan, W., and Kamoun, S. RXLR effectors of plant pathogenic oomycetes. Curr. Opin Microbiol. 10:332-338.

Nürnberger, T. and Brunner, F. 2002. Innate immunity in plants and animals: Emerging parallels between the recognition of general elicitors and pathogen-associated molecular patterns. Curr. Opin. Plant Biol. 5:318-24.

Ong, L. E., and Innes, R. W. 2006. AvrB mutants lose both virulence and avirulence activities on soybean and Arabidopsis. Mol. Microbiol. 60:951-962.

Rooney, H. C., Van't Klooster, J. W., van der Hoorn, R. A., Joosten, M. H. Jones, J. D., and de Wit, P. J. 2005. Cladosporium Avr2 inhibits tomato $\mathrm{Rcr} 3$ protease required for Cf-2-dependent disease resistance. Science 308:1783-1786.

Sambrook, J., and Russell, D. W. 2001. Molecular Cloning. Cold Spring Harbor Laboratory Press, Cold Spring Harbor, New York, U.S.A.

Schneider, D. S. 2002. Plant immunity and film Noir: What gumshoe detectives can teach us about plant-pathogen interactions. Cell 109:537-540.

Tian, M., Huitema, E., Da Cunha, L., Torto-Alalibo, T., and Kamoun, S. 2004. A Kazal-like extracellular serine protease inhibitor from Phytophthora infestans targets the tomato pathogenesis-related protease P69B. J. Biol. Chem. 279:26370-26377.

van der Hoorn, R. A., and Kamoun, S. 2008. From Guard to Decoy: A new model for perception of plant pathogen effectors. Plant Cell. 20:200917.

Van der Hoorn, R. A., Laurent, F., Roth, R., and De Wit, P. J. 2000. Agroinfiltration is a versatile tool that facilitates comparative analyses of Avr9/Cf-9-induced and Avr4/Cf-4-induced necrosis. Mol. Plant-Microbe Interact. 13:439-446.

Vleeshouwers, V. G. A. A., Driesprong, J.-D., Kamphuis, L. G., TortoAlalibo, T., van't Slot, K. A. E., Govers, F., Visser, R. G. F., Jacobsen, E., and Kamoun, S. 2006. Agroinfection-based high throughput screening reveals specific recognition of INF elicitins in Solanum. Mol. Plant Pathol. 7:499-510.

Whisson, S. C., Boevink, P. C., Moleleki, L., Avrova, A. O., Morales, J. G., Gilroy, E. M., Armstrong, M. R., Grouffaud, S., van West, P., Chapman, S., Hein, I., Toth, I. K., Pritchard, L., and Birch, P. R. 2007. A translocation signal for delivery of oomycete effector proteins into host plant cells. Nature 450:115-118.

\section{AUTHOR-RECOMMENDED INTERNET RESOURCE}

Joint Genome Institute website: genome.jgi-psf.org 